ANL- 6775

Reactor Technology

(TID-4500, 24th Ed.)

$A E C$ Research and

Development Report

\author{
ARGONNE NATIONAL LABORATORY \\ 9700 South Cass Avenue \\ Argonne, Illinois 60440
}

\author{
PERFORMANCE CHARACTERISTICS OF EBWR \\ FROM 0-100 Mwt \\ by \\ E. A Wimunc, M. Petrick, \\ W. C. Lipinski, and H. Iskenderian \\ Reactor Engineering Division
}

September 1963

Reproduced from Paper No CN-15/3 presented at the IAEA Conference on Operating Experience with Power Reactors, Vienna, Austria, June 4-8, 1963, sponsored by the International Atomic Energy Agency.

Operated by The University of Chicago under

$$
\text { Contract W-31-109-eng-38 }
$$
with the

U.S. Atomic Energy Commission 


\section{DISCLAIMER}

This report was prepared as an account of work sponsored by an agency of the United States Government. Neither the United States Government nor any agency Thereof, nor any of their employees, makes any warranty, express or implied, or assumes any legal liability or responsibility for the accuracy, completeness, or usefulness of any information, apparatus, product, or process disclosed, or represents that its use would not infringe privately owned rights. Reference herein to any specific commercial product, process, or service by trade name, trademark, manufacturer, or otherwise does not necessarily constitute or imply its endorsement, recommendation, or favoring by the United States Government or any agency thereof. The views and opinions of authors expressed herein do not necessarily state or reflect those of the United States Government or any agency thereof. 


\section{DISCLAIMER}

Portions of this document may be illegible in electronic image products. Images are produced from the best available original document. 
Page

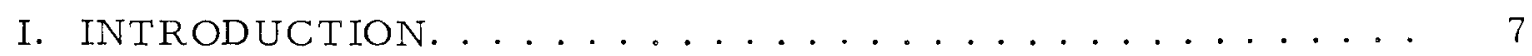

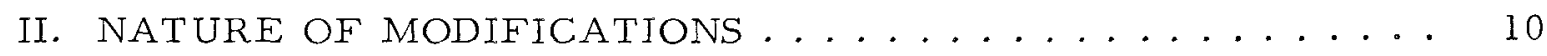

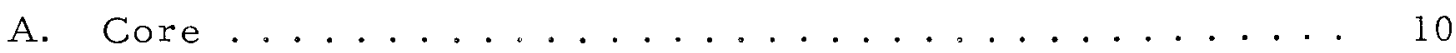

1. Fuel Assemblies .................... 10

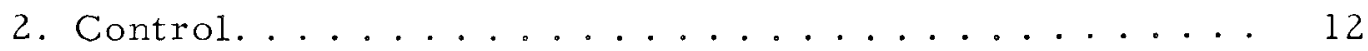

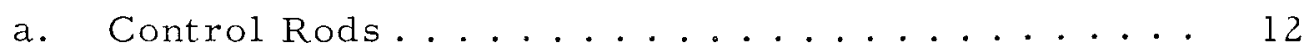

b. Soluble Porson (Boric Acid) ............ 12

B. Core Structure and Pressure Vessel Internals ....... 13

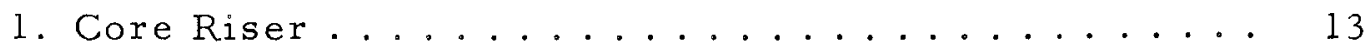

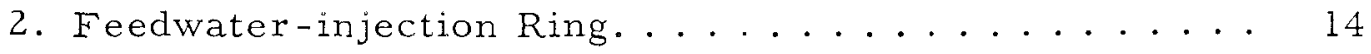

3. Steam-discharge System ................. 14

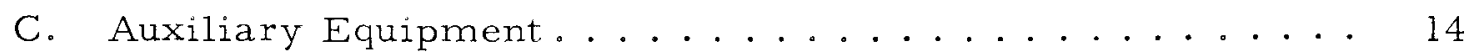

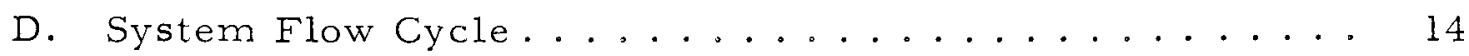

III. TEST PROGRAM, RESULTS, AND SPECIFIC OBSERVATIONS . 17

A. Thermal Hydraulic Performance............ 17

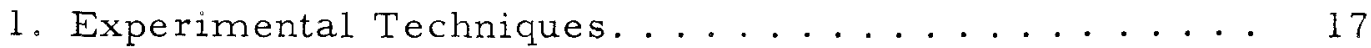

a. Statıc Pressure Differentials.......... 17

b. Total Recirculation Flow Rate .......... 18

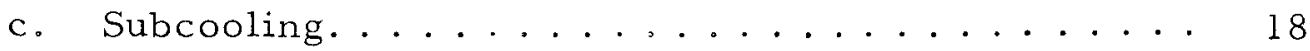

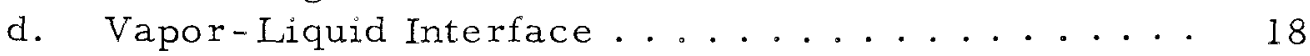

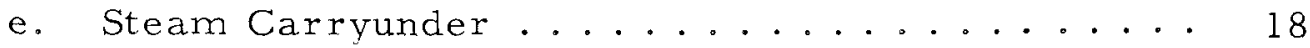

f. Liquid Carryover.................... 19

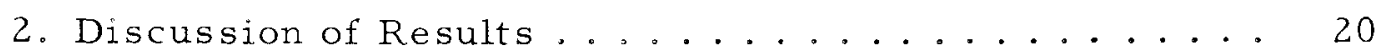

a. Total Reactor Recirculation Flow Rates....... 21

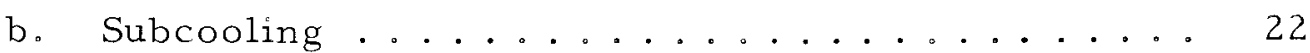

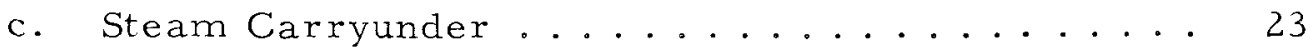

d. Steam Volume Fractions in Riser and Downcomer. 24

e. True Liquid Level ............... 27

f. Liquid Carryover.............. 28 


\section{TABLE OF CONTENTS}

Page

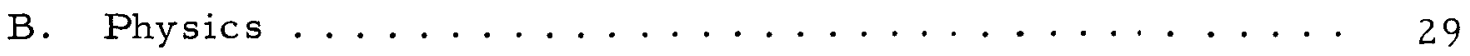

1. Functions of Spike Fuel Assemblies. . . . . . . 29

2. Core Parameters.................. 30

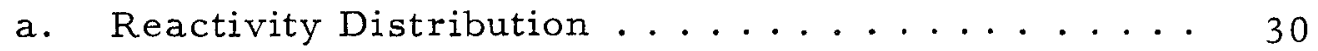

b. Power Coefficient................ 31

c. Void Coefficient of Reactivity........... 32

d. Neutron-flux Distributions............. 34

C. Specific Observations .................... 34

1. Fuel Assemblies ................... 34

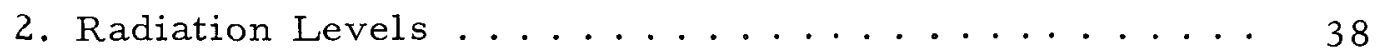

a. Transport of Corrosion Products ......... 38

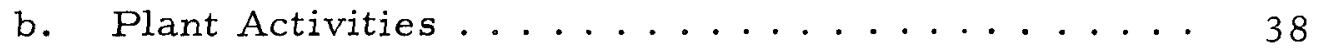

c. Fission Gas Release............... 39

3. On the Use of Soluble Poisons (Boric Acid) ....... 41

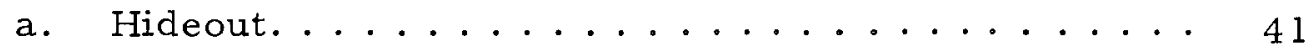

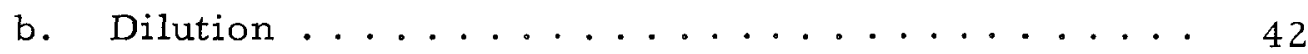

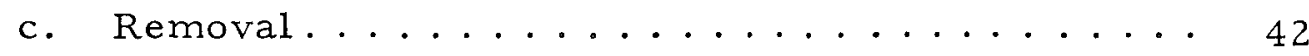

d. Monitoring ................... 42

D. Reactor Transfer Function Measurements ......... 43

1. Methods ....................... 43

a. Sinusoidal Reactivity Input............ 43

b. Autocorrelation ................. 45

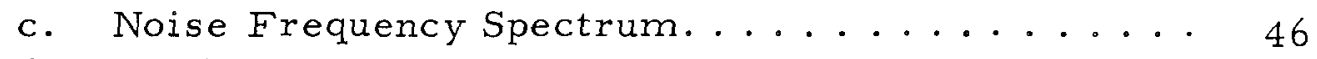

d. Random Reactivity Input ............. 49

2. Summary ........................ 50

ACKNOWLEDGMENT ........................ 51

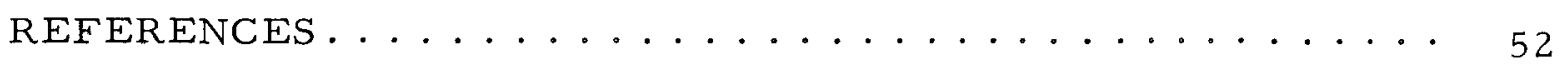

SELECTED READING LIST .................... 53 


\section{LIST OF FIGURES}

No.

Title

Page

1. EBWR Plate-type Fuel Assembly .............. 10

2. EBWR Spike Fuel Rod Assembly and Frame.......... 11

3. Final EBWR 100-Mwt Core Loading. ............. 12

4. Modified Reactor Vessel and Internals ............. 13

5. EBWR 100-Mwt Flow Diagram ............ 15

6. Location of Instrumentation in EBWR Pressure Vessel . . . 17

7. Total Recirculation Flow Rate as a Function of Reactor Power at 600 psig and Various True Mixture Interface

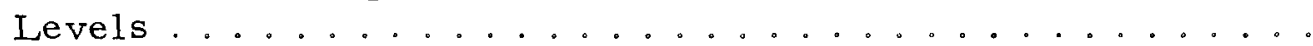

8. Core Inlet Velocity as a Function of Reactor Power and Various True Mixture Interface Levels ............ 21

9. "Map" of Reactor Subcooling as a Function of Reactor Power and Various True Mixture Interface Levels...........

10. Steam Carryunder as a Function of Reactor Power and True Mixture Interface Levels .................

11. Steam Volume Fraction at Periphery of Riser as a Function of Reactor Power at 600 psig and Various True Mixture Interface Levels. .........................

12. Steam Volume Fraction in Upper Region of Downcomer as a Function of Reactor Power and Various True Mixture

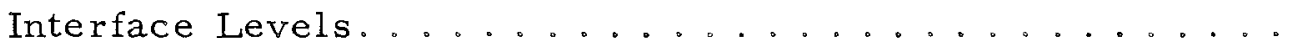

13. Steam Volume Fraction in Lower Region of Downcomer as a Function of Reactor Power and Various True Mixture Interface Levels..................... 25

14. Effect of Subcooling on Bubble Collapse Time ........ 26

15. Steam Volume Fraction as a Function of Reactor Power, Showing Void Pattern Expected in Upper Region of

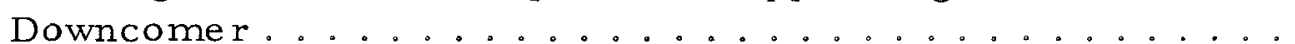

16. Height Differential between Actual Interface Level and Water Column Level as a Function of Reactor Power and Various True Mixture Interface Levels ............

17. Per cent Liquid Carryover as a Function of Reactor Power, Showing Comparison of Data Obtained from Three Sources..

18. Per cent Liquid Carryover as a Function of Distance above Vapor Interface for Various Superficial Vapor Velocities ... 


\section{LIST OF FIGURES}

No.

$\underline{\text { Title }}$

$\underline{\text { Page }}$

19. Liquid Carryover as a Function of Reactor Power and Various Water Column Levels. (Data from Heat Balance on

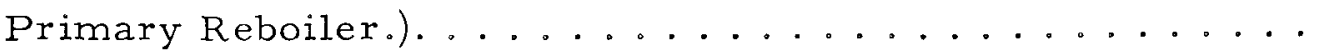

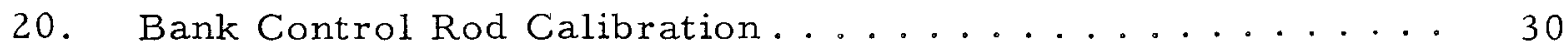

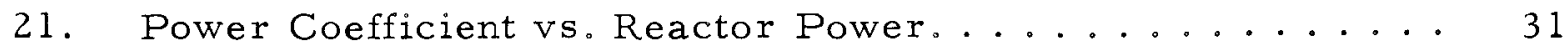

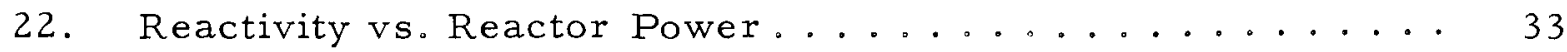

23. Mean Core Steam Volume Fraction vs. Reactor Power .... 33

24. Thermal Neutron Flux Isogram Plot for Reactor Power of 40 Mwt and Soluble Poison Concentration of 25 ppm Boric

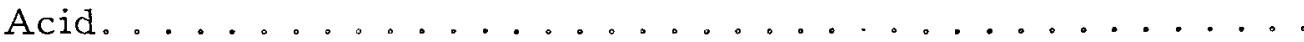

25. Thermal Neutron Flux Isogram Plot for Reactor Power of $40 \mathrm{Mwt}$ and Soluble Poison Concentration of $1200 \mathrm{ppm}$ Boric

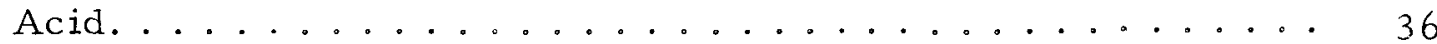

26. Location of Radiation Measurement Points in Reboiler

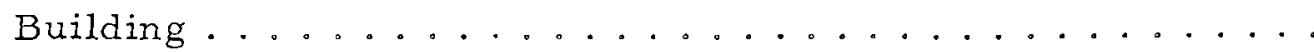

27. EBWR Fission Gas Release vs. Reactor Power .......

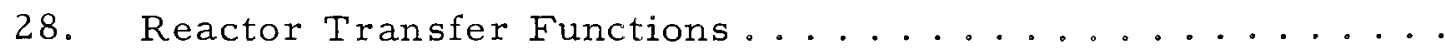
44

29. Block Diagram of Reactor with Feedback .......... 45

30. Reactor Gain and Phase Stability.............. 46

31. Reactor Power vs. Time as Recorded Directly from Ioniza-

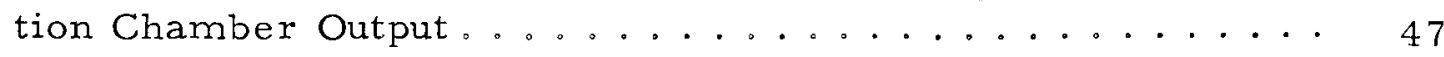

32. Autocorrelation Function at $100 \mathrm{Mwt} \ldots \ldots . \ldots 47$

33. Noise Frequency Spectrum at 100 Mwt .......... 48

34. Discrete-interval Binary Noise.............. 49

35. Velocity-limited, Discrete-interval, Binary Noise ...... 49

36. Velocity-limited, Discrete-interval, Binary Noise Frequency

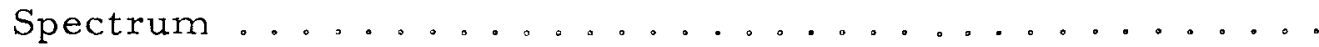

37. Transfer Function at $40 \mathrm{Mwt}$ Obtained by Cross-correlation of Neutron Flux Output with Binary Noise Reactivity Input... 
No.

I. Reactor Design Data................... 8

II. Accumulated Reactor and Generator Operation .........99

III. Control Rod Positions vs. Power. . . . . . . . . . . 32

IV. Radiation Levels in Containment Shell $(\mathrm{mr} / \mathrm{hr}) \ldots \ldots . . . .39$

V. Root-mean-square Noise under Various Reactor Operating Conditions........................ 48 


\title{
PERFORMANCE CHARACTERISTICS \\ OF EBWR FROM 0-100 Mwt
}

\author{
by
}

\author{
E. A. Wimunc, M. Petrick, \\ W. C. Lipinski, and H. Iskenderian
}

\section{INTRODUCTION}

The Experimental Boiling Water Reactor (EBWR) was originally constructed to demonstrate the feasibility of a direct-cycle, naturalcirculation, boiling-water reactor integrated power plant. The reactor was designed to produce $20,000 \mathrm{kw}$ of heat in the form of 600-psig saturated steam which was fed directly to a turbogenerator, generating about $5,000 \mathrm{kw}$ of electricity. This power level was considered as a minimum value for producing useful information which could be extrapolated and used in the design of large, central-station power plants. The reactor achieved criticality during December 1956, and began full-power operation at $20 \mathrm{Mwt}$ on December 29, 1956.

Subsequent experiments at power levels ranging from $20 \mathrm{Mwt}$ to $40 \mathrm{Mwt}$ indicated that stable operation at powers as high as $66 \mathrm{Mwt}$ was possible with the initial 4-ft-diameter core. This was affirmed in 1958 by the short-term operation of the plant at 61.7 Mwt. Further power increase at this time was precluded by the feedwater pumps which were operating at maximum capacity.

A detailed study of EBWR stability was made by taking a series of transfer function measurements relating flux or power level to reactivity input. Data at various power levels, steam pressures, and control rod positions were accumulated, analyzed, and extrapolated to predict reactor performance : higher power levels. The results of this study were the subject of a p per presented at the 1958 Geneva Conference. (1)

Subsequent analyses and projection of these data to a 5-ft-diameter core indicated that with some modification of the core structure and pressure vessel internals, and with additional heat-removal equipment, EBWR could operate at or near $100 \mathrm{Mwt}$. In July 1959, the reactor plant was shut down preparatory to the onset of proposed modifications.

The modification of EBWR represented another successful pioneering endeavor at the birthplace of nuclear reactors. In addition to the system changes and additions that were effected, the core was instrumented extensively. This entailed development of unique instrumentation techniques to ensure quantitative data about the performance characteristics of the reactor at elevated power levels. 
On May 25, 1962, permission was granted by the U.S. Atomic Energy Commission to operate EBWR at power levels up to $100 \mathrm{Mwt}$. Administrative approval by the International Atomic Energy Agency was granted on July $11,1962$.

Upon completion of the modifications, the reactor was subjected to a series of stability tests at successive power level increases up to $70 \mathrm{Mwt}$. After careful analysis and scrutiny of the data, it was decided that operation at $100 \mathrm{Mwt}$ could be achieved safely.

This paper summarizes the significant observations and reactor performance data evolved during the period from July 1959 to December 6, 1962. The latter date marked the shutdown and termination of the watercooled reactor program at the Laboratory. Most of the data was obtained during the last 6 months of operation.

The pertinent reactor design data are summarized in Table I. Table II lists the reactor-generator operation and output accumulated at the time of shutdown.

Table I

REACTOR DESIGN DATA

Maximum Power

Maximum Operating Pressure

Number of Elements

Fuel Subassembly

Plate

Spike

Clad

Total Fuel Content

Active Core Diameter and Height

Total Fuel Heat Transfer Area in Core
$100 \mathrm{Mwt}$

600 psig

147

115 (metallic U)

$32\left(\mathrm{UO}_{2}\right)$

Zircaloy -2

6.2 tons $(5700 \mathrm{~kg})$

$\sim 90 \mathrm{~kg} \mathrm{U} \mathrm{U}^{235}$

$5 \times 4 \mathrm{ft}$

$2480 \mathrm{ft}^{2}$
Calculated Heat Transfer Data

Average Power Density, kw/liter*

Average Heat Flux, Btu/(hr) $\left(\mathrm{ft}^{2}\right)$

Maximum Heat Flux, Btu/(hr) $\left(\mathrm{ft}^{2}\right)$

Per Cent of Power Removed

Equivalent Diameter of Coolant Channel, in.
Central

Thin

Enriched

Zone

113.3

225,353

346,000

31.25

0.781
Outer

Thin Thick

Spike Enriched Enriched

Zone Zone Zone

130

147,160

246,100

23.27

0.45
92.8

185,000

283,605

11.37

0.781
77.1

118,000

172,000

34.11

0.653

\footnotetext{
*Kilowatt per liter of coolant in core.
} 
Table II

ACCUMULATED REACTOR AND

GENERATOR OPERATION

Reactor

hr

Mw-hr

Generator

hr

Mw-hr
Total to

$7 / 3 / 59$
8,745

35,006
Total to

$12 / 6 / 62$

11,225

211,509

15,665

294,028

10,603

39,696 


\section{NATURE OF MODIFICATIONS}

A. Core

\section{Fuel Assemblies}

The core of the modified EBWR consisted of the original 115 plate-type fuel assemblies plus 32 enriched spike assemblies. Four variations of plate-type assemblies (see Fig. 1) were employed: the plates were thin (0.212 in.) or thick (0.280 in.), and contained natural or enriched $\left(1.44 \% \mathrm{U}^{235}\right)$ uranium. The natural uranium plates comprised a heat-treated ternary alloy of $93.5 \mathrm{w} / 0$ natural uranium $\left(0.72 \% \mathrm{U}^{235}\right), 1.5 \mathrm{w} / 0$ niobium, and $5 \mathrm{w} / \mathrm{o}$ zirconium, with Zircaloy -2 cladding. The side plates were made thick enough ( $\frac{1}{16}$ in.) to weld to the fuel plates and were perforated to allow stretching (creep) in the event of elongation of the fuel plate under irradiation. The enriched uranium plate assemblies were structurally similar but contained uranium enriched to $1.44 \%$ in $\mathrm{U}^{235}$.

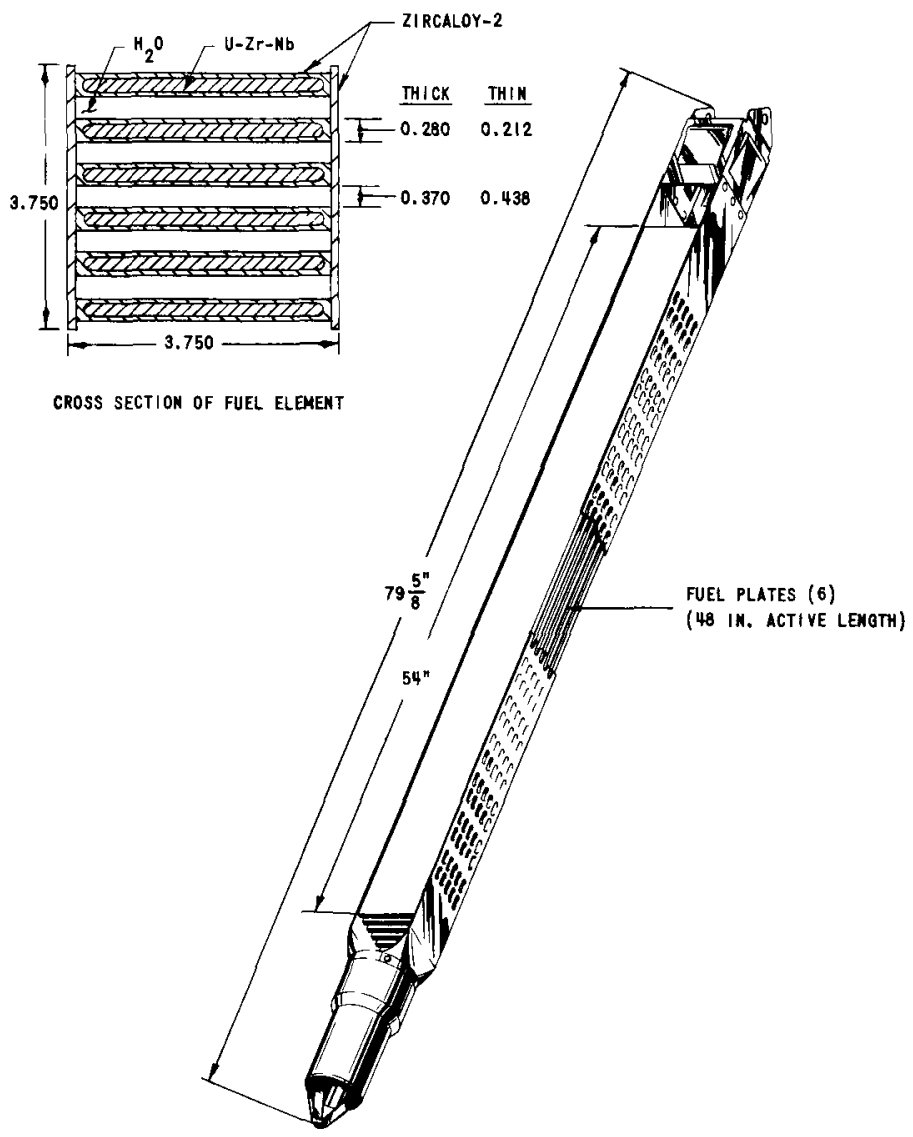

$112-2623$

Fig. 1. EBWR Plate-type Fuel Assembly 
The concept of a spiked fuel assembly was predicated on the desire to minimize research and development of new fuel assemblies and to utilize the maximum number of original EBWR fuel assemblies. Each spike assembly (see Fig. 2) was comprised of 49 fuel rods. Each fuel rod consisted of $\mathrm{UO}_{2}$ fuel (>90\% enriched in $\mathrm{U}^{235}$ ) dispersed in a $\mathrm{ZrO}_{2}+\mathrm{CaO}-$ matrix pellet and clad with Zircaloy-2. The gap between the pellet and the clad was filled with helium. Some flexibility in the worth of each spike was obtained by adding $1.1 \%$ boron-stainless steel poison strips to the spike frames. These strips were easily removed when additional reactivity was required. The worth of a spike element containing boron strips and located in the spike zone was as follows:

Spike assembly containing 2 boron strips: $\quad 0.14 \% \triangle \mathrm{k}$;

Spike assembly containing $\mathrm{l}$ boron strip: $0.23 \% \triangle \mathrm{k}$;

Spike assembly without boron strips: $\quad 0.32 \% \triangle \mathrm{k}$.

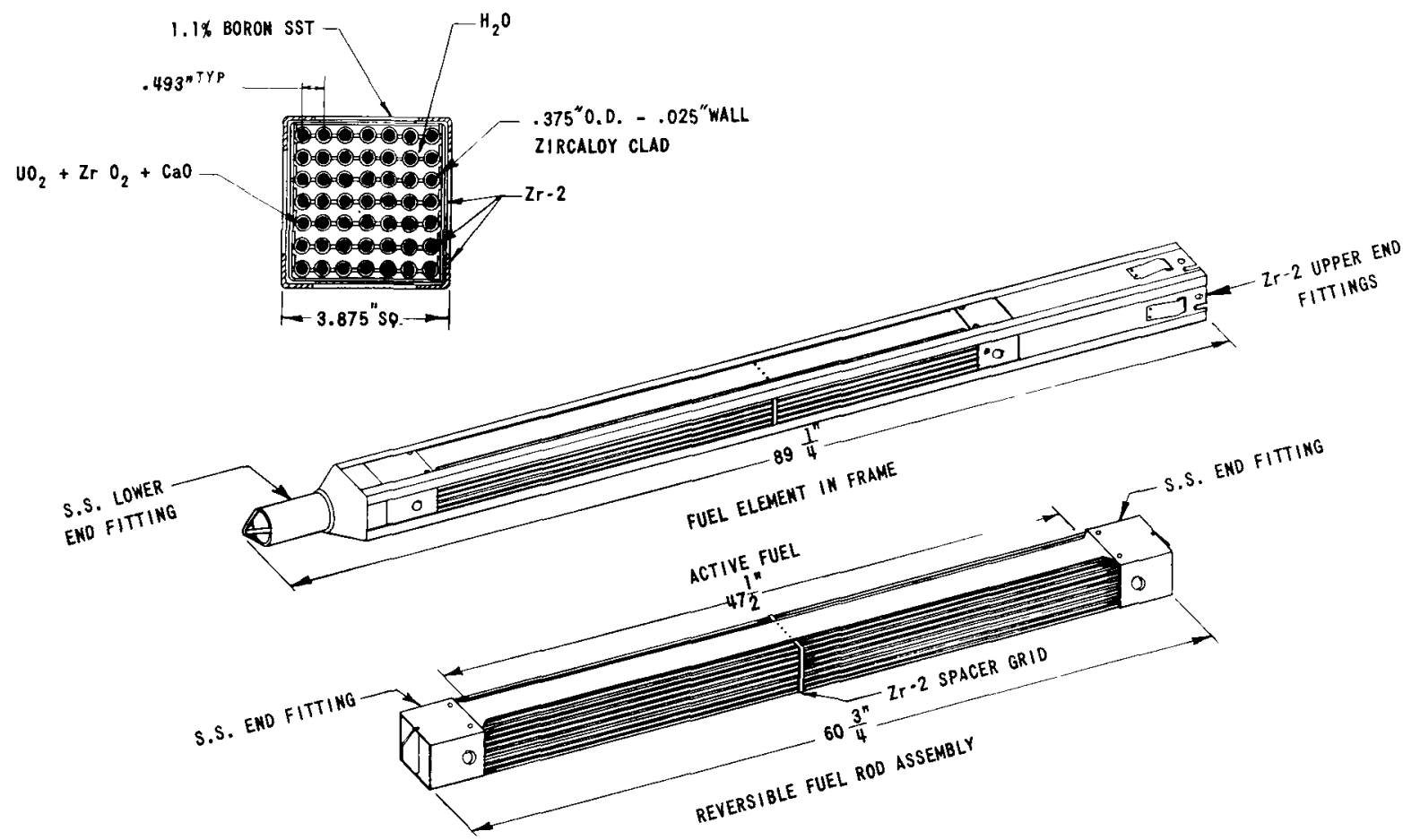

$112-2624$

Fig. 2. EBWR Spike Fuel Rod Assembly and Frame

A stepwise approach in loading the reactor to the final configuration required a number of core changes, which included fuel rearrangement, fuel additions, and removal of some burnable poison strips from the spike assemblies, consistent with the established loading criteria. These criteria were:

(1) The system must always have the capacity to be made subcritical at any time by use of only eight of the nine control rods and boric acid. 
(2) No loading was to be installed which would be critical with all nine rods fully inserted and with no boric acid in the reactor core.

Figure 3 shows the final arrangement of fuel assemblies in the core for operation at $100 \mathrm{Mw}$.

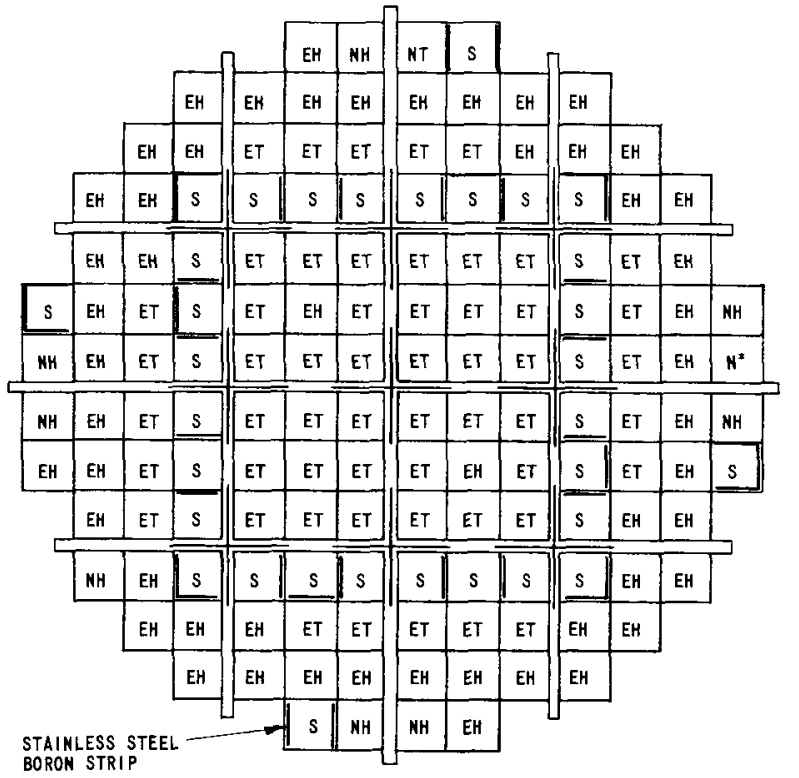

EBWR-CORE IA; LOADING \$63 (REV).

52-EH = ENRICHED HEAVY

54-ET = ENRICHED THIN

8-NH = MATURAL HEAVY

I-NT = MATURAL THIN

$32-S=$ SPIKE

$I-N^{*}=$ SOURCE

\section{$112-2621$}

Fig. 3. Final EBWR 100-Mwt Core Loading

\section{Control}

a. Control Rods.

Primary reactor control was effected by nine cross-shaped rods: each 60 in. long, 10-in. wide, $0.25 \mathrm{in}$. thick, and fabricated from Type 304 stainless steel containing $2 \mathrm{w} / \mathrm{o}$ boron. The 10 -in.wide portion of the control rod follower was made of Zircaloy-2. These rods were identical with the original set of rods placed in the EBWR in 1956. The central control rod was replaced by a 4-ft-long hafnium rod. This rod was used in conjunction with an oscillator mechanism to obtain transfer function data.

\section{b. Soluble Poison}

(Boric Acid). In addition to the nine control rods, boric acid solution was used with the final core loading to provide a sufficient range of 'reactivity control to in-

sure a clean, cold shutdown margin and yet permit reaching a power level of $100 \mathrm{Mwt}$. The final core loading required $1060 \mathrm{ppm}$ of boric acid in the reactor water in order to meet the 8 -rod shutdown criteria. The reactor was also subcritical without boric acid and with all nine rods fully inserted. The void coefficient remained negative at all concentrations up to $2640 \mathrm{ppm}$, which was the maximum range of interest. Each gram of boric acid per gal of reactor water (264 ppm) was sufficient to hold down about $1 \% \rho$.

Boric acid having a concentration of $182 \mathrm{gm} / \mathrm{gal}$ was stored in a 200-gal tank. The solution could be pumped into the reactor feedwater line under pressure, pumped into the condenser hotwell, or into the lowpressure boric acid-spray ring located within the reactor vessel. Positive displacement pumps were utilized and could be energized from the control room. The maximum pumping rate was $2.8 \mathrm{gpm}$ of $182 \mathrm{-gm} / \mathrm{gal}$ solution. The reactor vessel has a normal water inventory of about 4,000 gal. 
B. Core Structure and Pressure Vessel Internals

The following modifications were designed primarily to increase recirculation flow rates in the reactor by approximately a factor of two in order to reduce the steam volume fractions in the core and, hence, loss of reactivity.

\section{Core Riser}

The new riser arrangement (see Fig. 4) basically consists of an addition to the original system, which was essentially the control rod

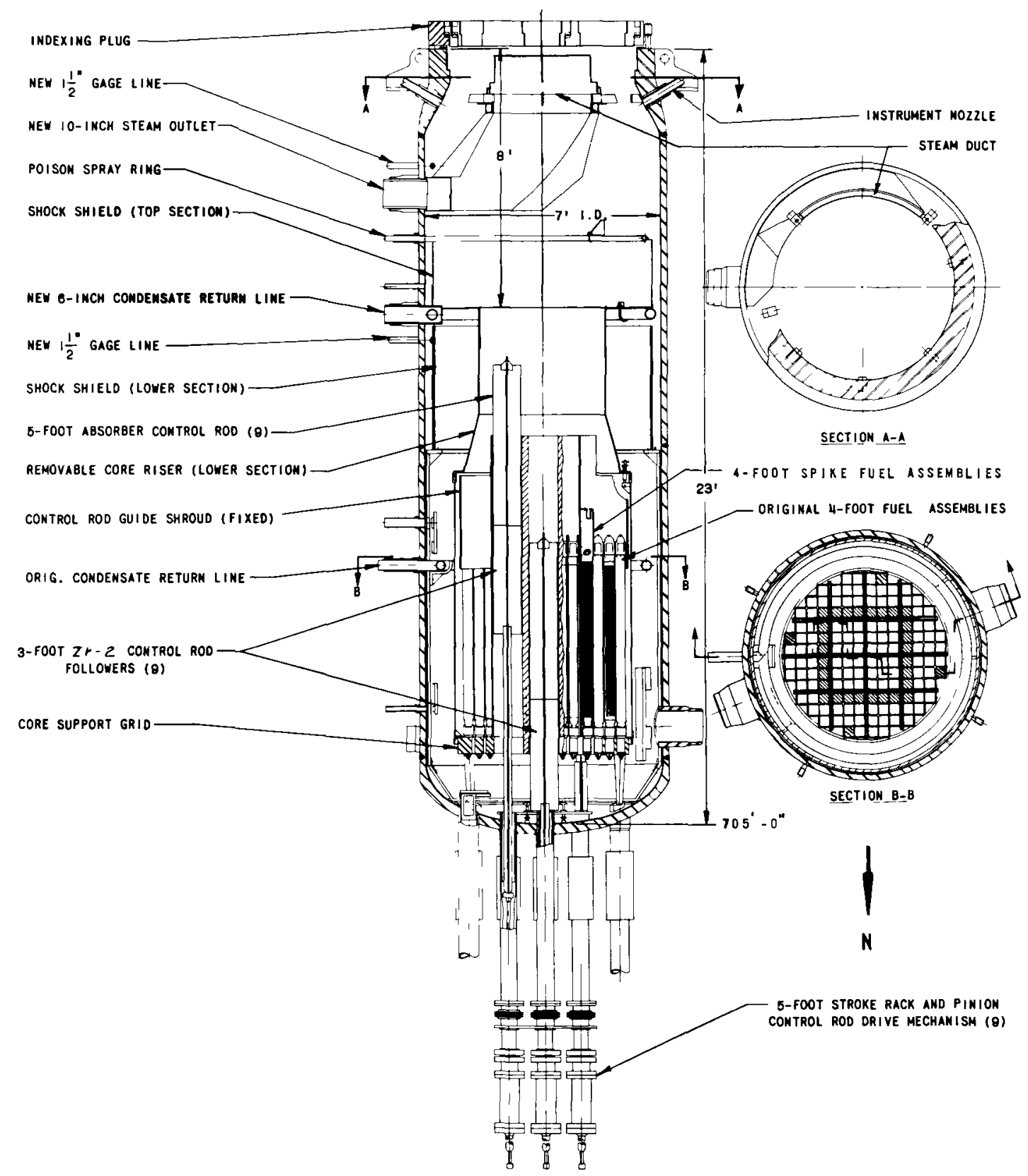


guide superstructure. The total height is approximately $7.5 \mathrm{ft}$ above the shroud. This height was chosen as the maximum feasible for maintaining the steam-water interface within a desired level range and for reducing the liquid carryover. The upper portion of the riser was necked down so that the increased downcomer area and resultant reduced water velocity would aid de-entrainment of steam in the downcomer.

In addition, a cylindrical shell was installed around the core to provide a tight closure between the riser and the core shroud. These modifications were intended to prevent any short circuiting of the fluid from the downcomer to peripheral riser sections and core due to static pressure differences inherent in such systems.

\section{Feedwater-injection Ring}

The effectiveness of the riser was enhanced by installing a new feedwater-injection ring just below the top of the riser. With this arrangement, steam carried under in the downcomer would be mixed with the influent cold feedwater and quenching would be initiated rapidly.

\section{Steam-discharge System}

The original steam-discharge ring and 6-in. outlet nozzle were removed from the pressure vessel, and the vessel penetration was enlarged to accommodate a 10-in. discharge nozzle. The larger size of outlet was necessary because of the increased steam loads at the higher powers. At $100 \mathrm{Mw}$, the steam load is approximately $300,000 \mathrm{lb} / \mathrm{hr}$. The steam is collected from the very top of the reactor vessel by a duct arrangement. The duct arrangement was installed to accommodate the high liquid levels brought about by the addition of the taller riser.

\section{Auxiliary Equipment}

Additional equipment installed within the containment shell included two feedwater filters, a deaerator, subcooler, two feedwater pumps, and an instrument air compressor. A 16-ft-long gauge board was installed in the control room. A major portion of the equipment was located external to the containment building (see Fig. 5).

\section{System Flow Cycle}

Figure 5 is a simplified flow diagram of the design of the $100-\mathrm{Mwt}$ reactor plant. The reactor was operated as a direct-cycle, boiling-water reactor, cooled and moderated by natural circulation of light water. Except for minor modifications, the 5-Mwt turbogenerator plant and associated equipment were operated in essentially the same manner as originally designed. The Reboiler Plant was operated in parallel to handle the increased 


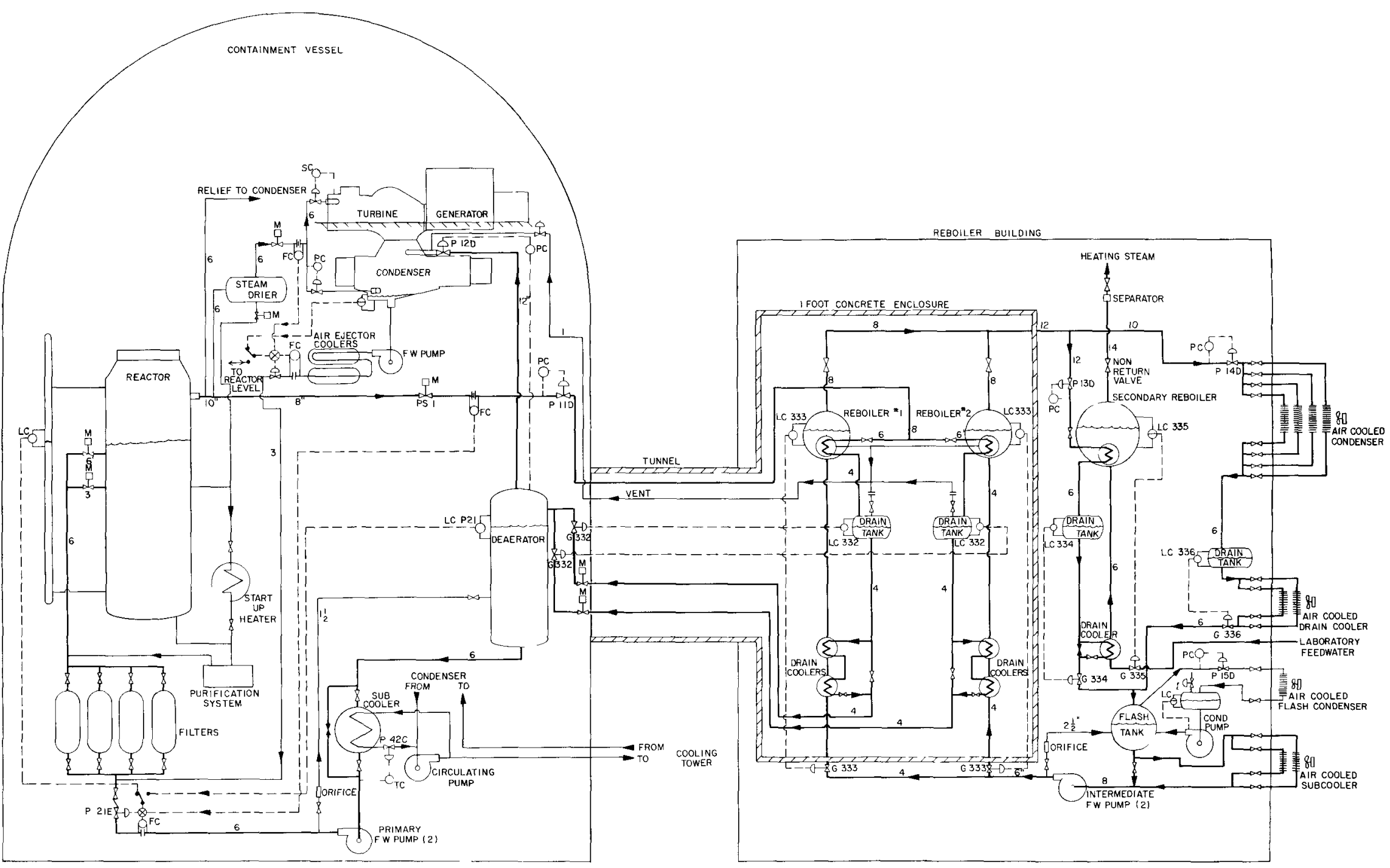

I $11-9480$

Fig. 5. EBWR 100-Mwt Flow Diagram 
heat output. Distribution of the thermal power output at $100 \mathrm{Mw}$ was as follows: $20 \mathrm{Mwt}$ was utilized by the Turbine Plant, and the balance (up to $80 \mathrm{Mwt}$ ) was absorbed by the Reboiler Plant.

The Reboiler Plant is divided into primary, intermediate, and secondary systems. The primary system is operated at a pressure of 560 psig saturated, the intermediate system at 350 psig saturated, and the secondary system at $200 \mathrm{psig}$. The secondary system operates at the same pressure as the Laboratory steam system. An intermediate system was incorporated to preclude radioactive steam from entering the Laboratory heating system. The Reboiler Plant can supply steam to the Laboratory or dissipate the energy through air-cooled heat exchangers. Details of the system and components are described in Reference 2 .

A number of problems were encountered with new equipment dur ing startup of the plant. The most predominant was maloperation of valves of all types. For the most part, the difficulties experienced were attributable to poor quality-control inspection by the vendor, or to improper installation by the contractor.

Pumps and controls also presented some operational problems. For example, the contractor had installed a pump-cutoff switch at the same level as the flash tank low-level alarm. This condition could have damaged the large, intermediate feedwater pumps, but fortunately was discovered in time and rectified.

All four sleeve bearings on both intermediate pumps required reworking. Insufficient lubrication caused the bearings to exceed normal operating temperatures. This situation was corrected by cutting grooves in the Babbitt metal bearings to enhance oil lubrication of the pump shafts.

Pipe lines to the level controller, sight gauge, and level alarm on both primary reboilers were revised to prevent particulate matter from plugging the lines and giving false indications.

After these and other equipment problems were corrected, plant performance was satisfactory. The modified plant was never subjected to shake-down operation in advance of the experimental program. As a result, the shake-down and the experimental program were carried out simultaneously in order to complete the program on schedule. 


\section{TEST PROGRAM, RESULTS, AND SPECIFIC OBSERVATIONS}

A. Thermal Hydraulic Performance

The thermal hydraulic test program with EBWR was focussed primarily on the vapor-liquid separation process and its effect on reactor performance. By adding the taller riser and raising the operating water level, the steam-water separation problem was greatly aggravated. This problem may be categorized into three main parts: (1) steam carryunder in the downcomer; (2) liquid carryover in the effluent steam; and (3) maintaining the actual vapor-liquid interface within a fixed height range.

Because the degree of primary steam separation that would take place within the reactor vessel was virtually unknown, and because of the tremendous effect this could have on reactor performance, the reactor was extensively instrumented to provide data or information on the recirculation flow rate; volumetric and weight fraction of vapor carryunder in the downcomer; reactor subcooling; riser void fractions; rate of quenching of entrained vapor in the downcomer; location of the true two-phase mixture interface within the reactor; and liquid carryover in the effluent steam.

\section{Experimental Techniques}

A complete description of the experimental techniques and a description of the thermal hydraulic instrumentation are given in Reference 4. Briefly, the data were acquired in the following manner.

a. Static Pressure Differentials. Static pressure differentials were measured with specially designed probes located at the positions shown in Fig. 6. Three probes were located in the downcomer,

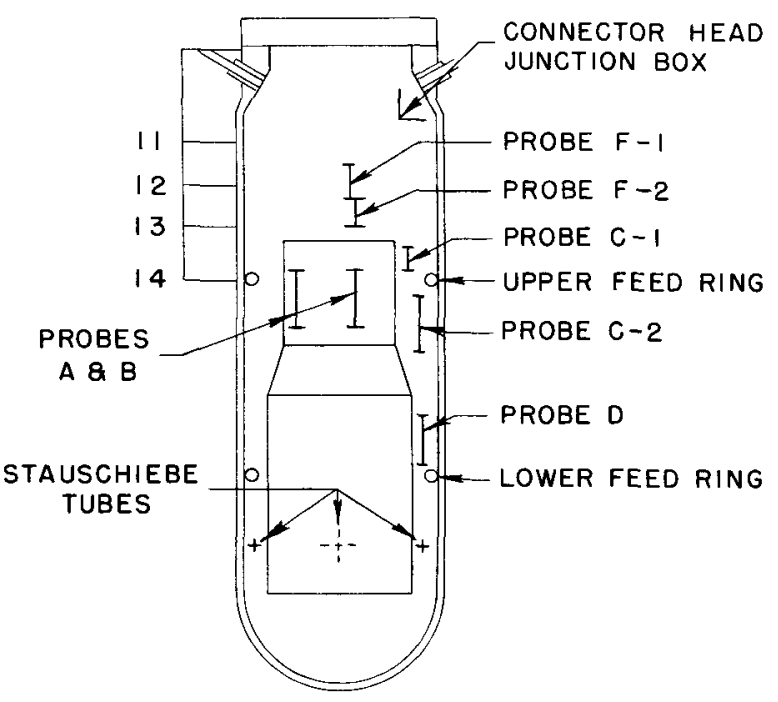

Fig 6

Location of Instrumentation in EBWR Pressure Vessel 
two in the riser, and two above the riser. The static pressure differentials are readily converted to steam volume fraction since frictional and acceleration pressure drops may be considered negligible. The three probes in the downcomer provided data on the magnitude of steam carryunder, how rapidly it was quenched, and the loss of driving head due to the voids present in the downcomer. Measurements of the steam volume fraction derived from the riser probes were used as a basis of comparison with the calculated performance characteristics of the reactor. The two probes located above the riser provided data on the vapor holdup and aided in locating the actual vapor liquid interface.

b. Total Recirculation Flow Rate. Because of the occurrence of carryunder, the recirculation flow rate can no longer be determined by the subcooling technique. An impact meter was selected for measurement of the recirculation velocity; more specifically, a stauschiebe tube, because it yields an approximately $50 \%$ greater reading than the normal impact meter such as a pitot tube, was chosen. Three stauschiebe tubes were placed in the downcomer approximately $120^{\circ}$ apart and at three different radii to obtain equal area readings.

c. Subcooling. Subcooling measurements were made with insulated, chromel-alumel the rmocouples sheathed in a tube (of $\frac{1}{16}$-in. OD). Six couples were located at various positions in the downcomer near the bottom of the reactor core. Three of the couples were attached to the stauschiebe tubes.

d. Vapor-Liquid Interface. The vapor-liquid interface was located by a series of differential pressure readings taken from five taps penetrating the reactor vessel in the region of riser discharge (see Fig. 6, positions $11,12,13$, and 14). By comparing the series of readings with equivalent lengths of pure steam and saturated water, the vapor-liquid interface can be pinpointed within a limited height range.

e. Steam Carryunder. The steam carryunder was calculated from the measured recirculation flow rates and subcooling by means of the following heat balances:

$$
\begin{aligned}
& \frac{W_{T}}{W_{T}-W_{I}}\left(h_{f}-h_{i n}\right)-\frac{W_{I}}{W_{T}-W_{I}}\left(h_{f}-h_{I}\right)+x_{D} h_{f g}=X_{R}^{\prime}\left(h_{f}-h_{M}\right) ; \\
& X_{R}=\frac{\left(Q / W_{T}\right)-\Delta H}{h_{f g}},
\end{aligned}
$$


where

$$
\begin{aligned}
\mathrm{W}_{\mathrm{T}} & =\text { total recirculation flow rate, } \mathrm{lb} / \mathrm{hr} \\
\mathrm{W}_{\mathrm{I}} & =\text { ion exchanger flow, } 1 \mathrm{~b} / \mathrm{hr} \\
\mathrm{h}_{\mathrm{f}} & =\text { enthalpy of saturated liquid, Btu/lb } \\
\mathrm{h}_{\text {in }} & =\text { enthalpy of inlet core coolant, } \mathrm{Btu} / \mathrm{lb} \\
\mathrm{h}_{\mathrm{I}} & =\text { enthalpy of ion exchanger effluent, Btu/lb } \\
\mathrm{X}_{\mathrm{D}} & =\text { steam quality in downcomer } \\
\mathrm{h}_{\mathrm{fg}} & =\text { heat of vaporization } \\
\mathrm{X}_{\mathrm{R}} & =\text { steam quality in riser } \\
\mathrm{X}_{\mathrm{R}}^{\prime} & =\text { ratio of } \mathrm{W}_{\mathrm{M}} / \mathrm{W}_{\mathrm{T}} \text { where } \mathrm{W} \mathrm{M} \text { is the feed waterflow rate, } 1 \mathrm{~b} / \mathrm{hr} \\
\mathrm{h}_{\mathrm{M}} & =\text { enthalpy of feed water, } \mathrm{Btu} / \mathrm{lb} .
\end{aligned}
$$

In the event that liquid carryover occurs in the effluent steam, the heat balance must be modified, and the following equation results:

$$
\frac{X_{D}}{X_{R}}=\frac{\left(W_{M} / W_{T}\right)\left(h_{f}-h_{M}\right)-\left(h_{f}-h_{i n}\right)}{\left(Q / W_{T}\right)-\left(h_{f}-h_{i n}\right)},
$$

where

$$
\begin{aligned}
Q & =\text { reactor power, } \mathrm{Btu} / \mathrm{hr} \\
\mathrm{W}_{\mathrm{M}} & =\text { feed water flow rate, } 1 \mathrm{~b} / \mathrm{hr} \\
\mathrm{W}_{\mathrm{T}} & =\text { total recirculation flow rate, } 1 \mathrm{~b} / \mathrm{hr} \\
\mathrm{X}_{\mathrm{D}} / \mathrm{X}_{\mathrm{R}} & =\frac{\text { pounds steam in downcomer }}{\text { pounds steam in riser }} .
\end{aligned}
$$

f. Liquid Carryover. Data on the magnitude of the liquid carryover were obtained from three sources. The principal and most accurate source was a series of heat balances on the secondary and primary heat-dissipation systems. A heat balance on the secondary system establishes the true reactor power. Knowing the true reactor power, the liquid carryover can then be computed by making a heat balance on the primary reactor system. In the case of EBWR, the heat balance was made with the primary reboiler which has as its heat source the reactor steam:

$$
X=\frac{W_{I E^{h_{f g}, I E}}}{W_{P R} h_{f g}, P R}
$$


where

$$
\begin{aligned}
\mathrm{W}_{\mathrm{IE}} & =\text { intermediate heat exchanger flow rate, } \mathrm{lb} / \mathrm{hr} \\
\mathrm{h}_{\mathrm{fg}, \mathrm{IE}} & =\text { heat of vaporization in the intermediate heat exchanger } \\
\mathrm{W}_{\mathrm{PR}} & =\text { primary reboiler flow rate, } \mathrm{lb} / \mathrm{hr} \\
\mathrm{h}_{\mathrm{fg}, \mathrm{PR}} & =\text { heat of vaporization in the primary reboiler. }
\end{aligned}
$$

Liquid carryover data were also obtained from the discrepancy between the measured feedwater and steam-discharge flow rates. When liquid carryover occurs, more feedwater is injected into the reactor than steam is withdrawn. This discrepancy is actually a measure of the rate of liquid carryover. The major uncertainity in the se data is the rate of steam flow. With large amounts of water in the steam, the measured steam rate is undoubtedly in error. The magnitude of the error is unknown. However, the carryover data obtained in this manner check well with values obtained by the heat-balance method.

The third method consisted of taking steam samples from sampling probes located 6 in., $14 \frac{1}{4}$ in., and $22 \frac{1}{2}$ in. below the steamdischarge duct. The samples were analyzed for the sodium-24 content. The results were compared with a sample of reactor water obtained from a sampling point in the downcomer. These data were used to establish carryover gradients as a function of steam dome height. Extrapolation to the height of the steam duct yields the actual liquid carryover.

\section{Discussion of Results}

A broad generalization of the results is as follows:

The reactor performance characteristics are governed directly by steam carryunder in the downcomer, liquid carryover in the effluent steam and, indirectly, by the location of the true water-steam interface in the vessel.

The effect of steam carryunder and liquid carryover on reactor performance is reflected in the core inlet subcooling and, hence, mean density of the core moderator. As the magnitude of the steam carryunder increases, the subcooling and moderator density decrease, since the mean steam volume fraction increases. The effects are reversed in the case of liquid carryover. In order to maintain a constant liquid inventory, an excess of cold feedwater is injected into the reactor. This increases the reactor subcooling and, hence, the reactivity. The excess water is expelled in the effluent steam. The carryover phenomenon radically alters the performance characteristics of the reactor. Under these conditions, it is not a normal direct-cycle boiling-water reactor; in a sense, it becomes a 
natural-circulation, dual-cycle reactor. The steam carryunder and liquid carryover are very sensitive to the true two-phase mixture interface level within the reactor vessel. As the interface is lowered, the carryunder rises rapidly and the carryover decreases. As the interface level is raised, the effects are opposite: carryunder decreases and carryover increases.

a. Total Reactor Recirculation Flow Rates. Figure 7 is a plot of the recirculation flow rate as a function of power. The magnitude of the flow rate in the lower power range is in agreement with earlier core analyses and extrapolation from EBWR data. Analyses indicated that a two-fold increase in flow rate could be expected with the additional riser height. However, the rate of increase of the recirculation velocity with power was not as large as predicted. The lower rate of increase of flow is attributed to loss of subcooling and, hence, of increased frictional resistance in the core resulting from steam carryunder in the downcomer. At power levels above $40 \mathrm{Mw}$, the flow rates tend to level off and are affected slightly by the true water-steam interface level. This is evidenced by the data scattering on the figure. This behavior is a result of the indirect effect of the interface height on the reactor subcooling through its effect on the liquid carryover and vapor carryunder.

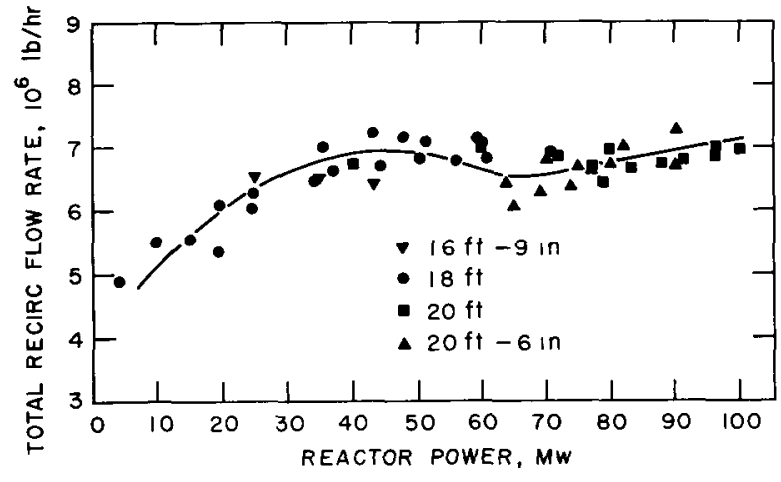

Fig. 7

Total Recirculation Flow Rate as a Function of Reactor Power at 600 psig and Various True Mixture Interface Levels

$112-2608$

These trends are more clearly shown in Fig. 8. The core inlet velocity data were obtained from turbine-type (Potter) flow meters installed in an instrument assembly near the center of the core.(5) Note the branching of the velocities as a function of the true interface height.

Fig. 8

Core Inlet Velocity as a Function of Reactor Power and Various True Mixture Interface Levels

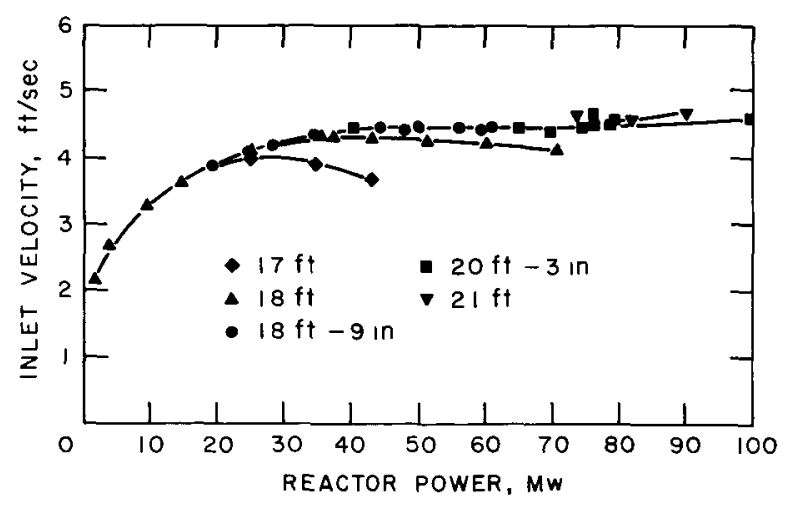

$112-2616$ (Rev. 2) 
The measured recirculation flow rates at power levels from $5 \mathrm{Mw}$ to $100 \mathrm{Mw}$ ranged from 4.7 to $7.25 \times 10^{6} \mathrm{lb} / \mathrm{hr}$. These correspond to a velocity ranging from 1.2 to $1.9 \mathrm{ft} / \mathrm{sec}$ in the upper downcomer.

When the make-up water was injected in the lower feedwater ring, the reactor appeared to have reached an equilibrium state. Over the power range from 5 to $20 \mathrm{Mw}$, the equilibrium recirculation flow rate was $\sim 4.7 \times 10^{6} \mathrm{lb} / \mathrm{hr}$. The equivalent velocity in the upper downcomer region is $1.2 \mathrm{ft} / \mathrm{sec}$. Under this mode of operation, the steam voids carried under are not collapsed until they reach the lower feedwater ring located below the riser. Therefore, the reactor stabilizes at a total flow just above the critical value for the initiation of steam carryunder. When the critical value is exceeded and steam carryunder commences, small amounts of steam produce large steam volume fractions, since the relative velocity of the two phases is essentially zero. This, in turn, immediately tends to reduce the net driving head by decreasing the density in the downcomer, and equilibrium conditions are rapidly achieved. The measured equilibrium downcomer velocity of $1.2 \mathrm{ft} / \mathrm{sec}$ agrees very well with laboratory loop data which show the threshold velocity for the initiation of steam carryunder at $600 \mathrm{psi}$ to be $1.3 \mathrm{ft} / \mathrm{sec}$.

b. Subcooling. Subcooling is, perhaps, the most important measurable reactor parameter, since it reflects the effects of carryover and carryunder, and the variation of other parameters such as recirculation flow and interface height. The effects of the vapor carryunder, liquid carryover, and true interface height are clearly evident in the subcooling "map" of EBWR (Fig. 9). The inception of liquid carryover can virtually be pinpointed. The seriousness and magnitude of the vapor carryunder is readily apparent. The magnitude of the liquid carryover can also be easily deduced.

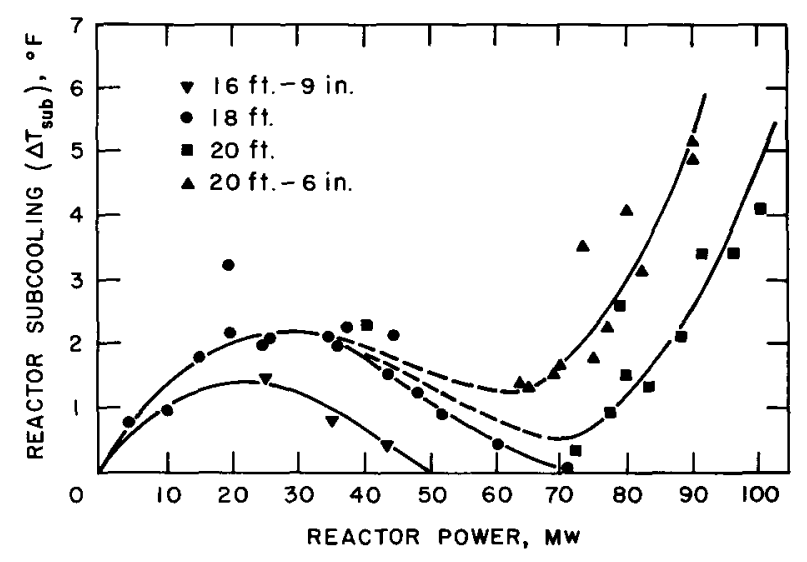

Fig. 9

"Map" of Reactor Subcooling as a Function of Reactor Power and Various True Mixture Interface Levels

$112-2619$

As evidenced by Fig. 9, reactor subcooling is extremely sensitive to the true mixture interface height. The family of curves obtained as a function of interface height merge at the low reactor powers. 
At an average interface height of $16 \mathrm{ft} 9 \mathrm{in.}$, the subcooling increases slightly with power, peaks at about $20 \mathrm{Mw}$, and then diminishes rapidly toward zero at about $50 \mathrm{Mw}$. This pattern of subcooling is a result of the steam carryunder in the downcomer. For normal reactor operation, if no steam carryunder is present, the subcooling increases continuously with power. At zero subcooling, the carryunder is $34.6 \mathrm{w} / \mathrm{o}$.

As the interface height is increased, the subcooling increases slightly and the peak occurs at a higher power level. This behavior is due to the fact that the carryunder is a function of the interface height. For the same power and flow, the carryunder decreases as the interface height increases; therefore, the subcooling is greater. The subcooling becomes zero at about $70 \mathrm{Mw}$.

At an interface height of $20 \mathrm{ft}$, the trend with power is the same in the lower range. However, at a power level of approximately $70 \mathrm{Mw}$, the subcooling increases sharply. The height of the steam dome has decreased to a point where, coupled with a superficial vapor velocity of $1.25 \mathrm{ft} / \mathrm{sec}$ in the steam dome, liquid carryover occurs. As the power is increased beyond this point, the vapor velocity also increases and the quantity of liquid carried over rises rapidly. The identical trend is seen in the data taken at an interface height of $20 \mathrm{ft} 6 \mathrm{in}$. The difference is that the subcooling is again slightly higher and the point of carryover is reached at a lower power level. This is due to the fact that the steam dome height is smaller.

c. Steam Carryunder. The steam carryunder in the reactor was calculated from a heat balance by means of the measured subcoolings

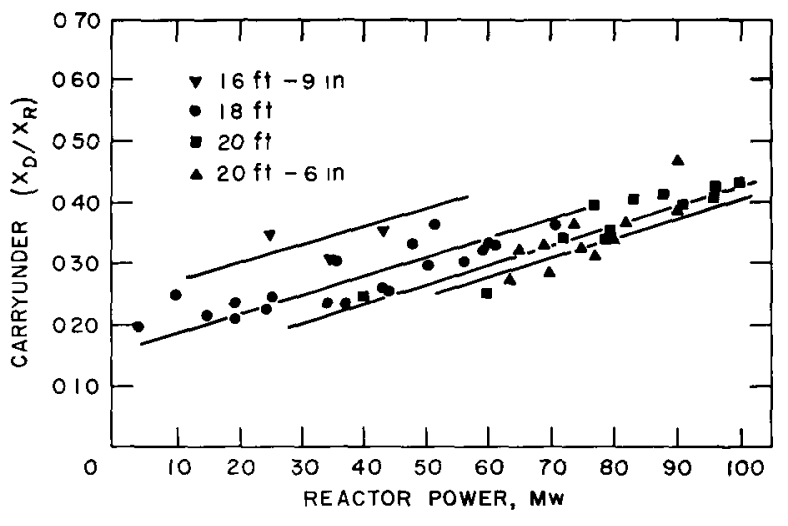

$112-2617$

Fig. 10. Steam Carryunder as a Function of Reactor Power and True Mixture Interface Levels and flow rates, as discussed previously. The steam carryunder as a function of power and interface height is plotted in Fig. 10. For these runs, the make-up water was injected in the upper feedwater ring. The quantity $\mathrm{X}_{\mathrm{D}} / \mathrm{X}_{\mathrm{R}}$ on the ordinate is equivalent to the fraction weight per cent of carryunder. The carryunder is substantial, $\sim 20 \%$, at the lower powers. This is due to the fact that the recirculation flow rates are of such magnitude that the threshold velocity for initiation of carryunder is exceeded even at the very low powers. As mentioned previously, the data indicated that the threshold water velocity for the initiation of carryunder is $1.2 \mathrm{ft} / \mathrm{sec}$. As the power is increased, the carryunder increases gradually to a value of $\sim 40 \%$ at $100 \mathrm{Mw}$ for an intermediate mixture 
interface height. That is, $40 \mathrm{w} / \mathrm{o}$ of all steam generated in the core is being entrained in the downcomer. The average water velocity in the downcomer at $100 \mathrm{Mw}$ was $1.9 \mathrm{ft} / \mathrm{sec}$.

It is interesting to note that the carryunder has exceeded the theoretical value of $34.6 \%$ (which corresponds to the point at which all subcooling is eliminated and recirculation of steam commences). This is due to the occurrence of liquid carryover.

The magnitude of vapor carryunder in the downcomer is somewhat startling. but corroborating evidence is gained from an analysis of the physics data as described in a later section.

Laboratory loop studies $(6)$ showed that as power is increased for a fixed recirculation velocity, the per cent of carryunder decreases, reaches a minimum, and then begins to increase. This sequence did not occur in the reactor, since the recirculation velocity continued to increase slightly with power. Once the threshold velocity for carryunder is passed, substantial increases in carryunder occur with small increases in velocity. In EBWR, the expected decrease of carryunder with increasing power apparently was nullified by the increase in the recirculation velocity. The overall effect was that the per cent of carryunder continued to increase with power.

d. Steam Volume Fractions in Riser and Downcomer. The steam volume fractions in the riser and the downcomer are shown in Figs. 11 through 13. The variation of the riser steam volume fraction with

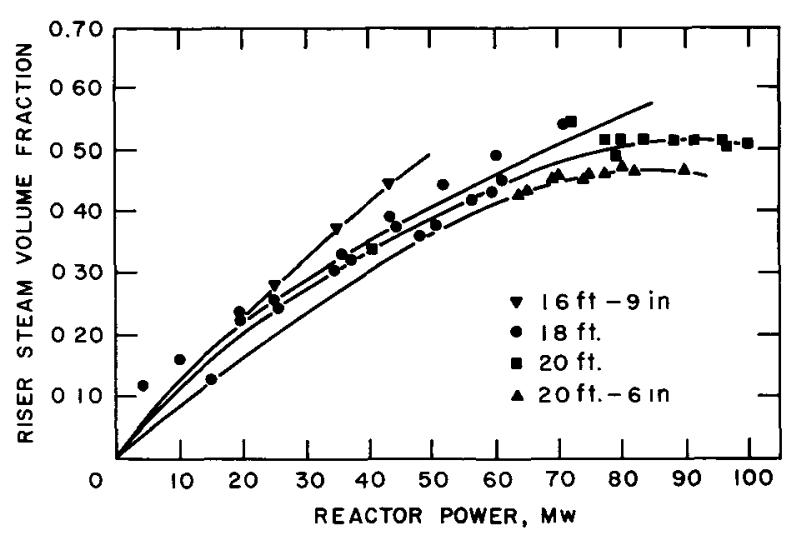

$112-2614$

Fig. 11. Steam Volume Fraction at Periphery of Riser as a Function of Reactor Power at 600 psig and Various True Mixture Interface Levels

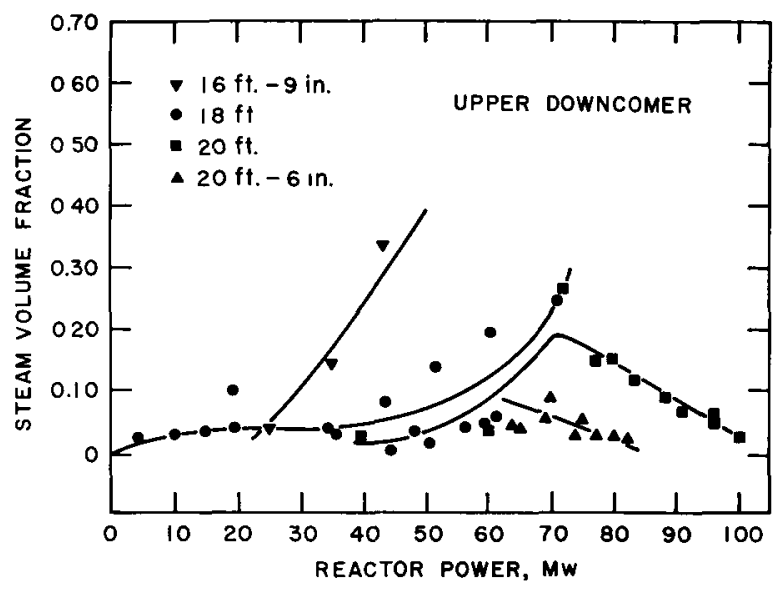

$112-2609$

Fig. 12. Steam Volume Fraction in Upper Region of Downcomer as a Function of Reactor Power and Various True Mixture Interface Levels 


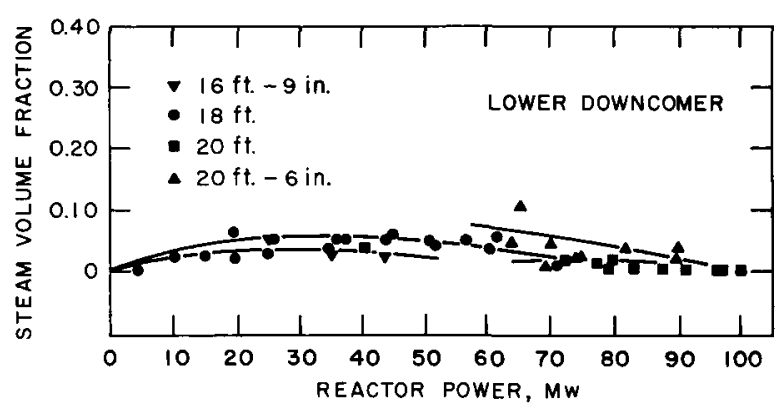

\section{$112-2606$}

power can also be scrutinized for the effects of liquid carryover and steam carryunder. In the lower power region (10-40 Mw), where the steam carryunder is predominant and the loss of the subcooling is rapid, the riser steam volume fraction rises rapidly. In the middle power range $(60-80 \mathrm{Mw})$, where the threshold of liquid carryover is reached, the void fraction tends to level off. In the very high powe $r$ range $(>80 \mathrm{Mw})$, the steam volume fraction tends to decrease. This behavior in the high power region is expected, since the subcooling is increasing rapidly with power due to carryover.

An indication of the change in the void content can be gained from a simple heat balance on the core:

$$
Q=W_{T}\left(\Delta h+X h_{f g}\right)
$$

or

$$
\mathrm{X}=\frac{\left(\mathrm{Q} / \mathrm{W}_{\mathrm{T}}\right)-\Delta \mathrm{h}}{\mathrm{h}_{\mathrm{fg}}},
$$

where $\mathrm{X}$ is the average mixture quality at the core exit. The average core and riser void fractions are roughly proportional to the average exit core mixture quality $X$. Therefore, the change in quality and, hence, change in voids was computed over the power intervals 70-100 $\mathrm{Mw}$.

The results of this analysis indicate that the rate of void fraction increase decreases as the power is increased. Between 80 and $90 \mathrm{Mw}$, there is virtually no change in exit quality; hence, the core and riser void fractions tend to remain nearly constant. Between 90 and $95 \mathrm{Mw}$, it appears that the void content actually decreases; hence, the reactivity increases. This behavior is shown in Fig. 11 and was corroborated by the control rod movements made over this power interval, as is discussed in Section III-B, Physics.

Data on the rate of quenching of the steam carried under were obtained in the lower downcomer and the upper downcomer where the riser was necked down (see Figs. 12 and 13). 
An insight into the collapse-rate pattern of the steam bubbles can be gained from a rough theoretical analysis of the problem. If it be assumed that the collapse of a vapor bubble in a subcooled liquid is governed primarily by the rate of heat transfer at its surface during the major fraction of its life time and that the bubble is moving in a quiescent fluid, a theoretical collapse rate can be computed. Undoubtedly, in a highly turbulent region the collapse rate of a bubble would be much higher

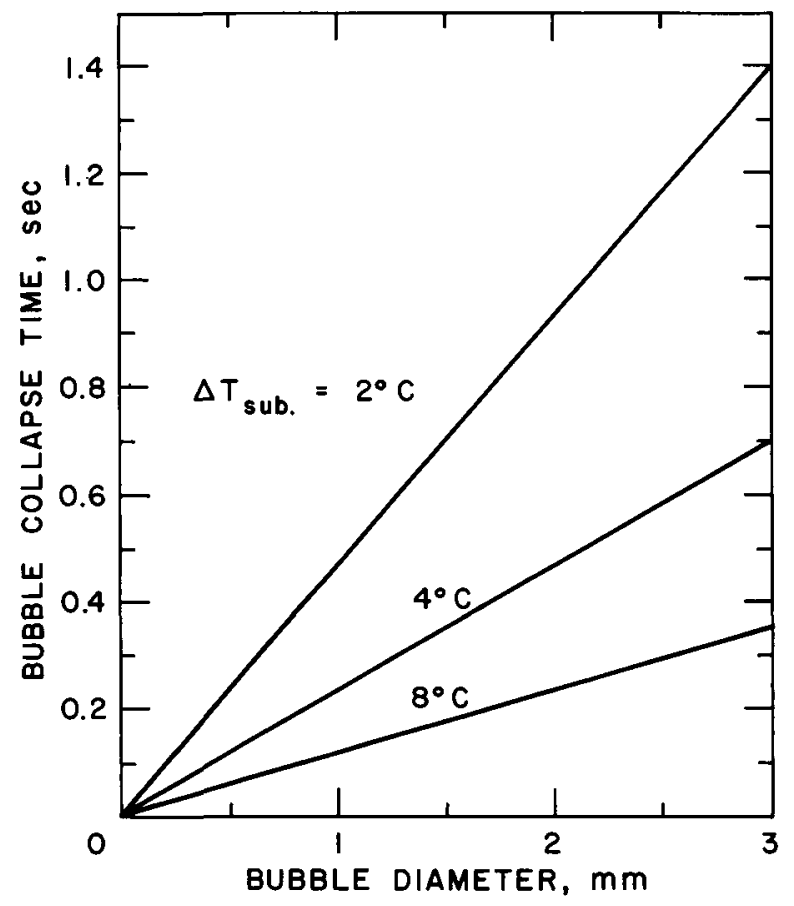

$112-2612$

Fig. 14. Effect of Subcooling on Bubble Collapse Time than predicted. However, the qualitative effect of subcooling on the collapse rate is considered fairly accurate.

Figure 14 shows the results of some rough calculations which illustrate the strong effect of subcooling on the collapse rate of bubbles of various diameters. As the subcooling increases, the time required to collapse the vapor bubble decreases. Thus, at the top of the downcomer, where the cold feedwater is injected, the subcooling is maximum, the collapse rate is likewise at a maximum, and one would expect a sudden large drop in the void content.

In an EBWR-type reactor in which cold feedwater is injected into the downcomer, the subcooling at core entry would vary from one degree at $\sim 10 \mathrm{Mw}$ to $\sim 12$ degrees at $100 \mathrm{Mw}$, assuming no carryunder. At low powers, the collapse rate is at a minimum; thus, a large quantity of steam carryunder would reflect a high steam volume fraction. As power is increased, the theoretical subcooling increases and thus the bubble collapse rate increases. Hence, for the same amount of steam carryunder, the steam volume fraction would be lower. In the very high power range (>75 Mw) where excess cold water is injected due to the liquid carryover, the collapse rate is even greater; and despite maximum carryunder, a low steam volume fraction would be expected. Moreover, because of liquid carryover, the steam volume fraction would decrease with power. Figure 15 illustrates the type of void pattern that was expected in the upper region of the downcomer. In the lower downcomer region virtually all the steam voids would be condensed because of the relatively long transient time involved. This is especially true in the very high power range, where an excess of feedwater is injected. 


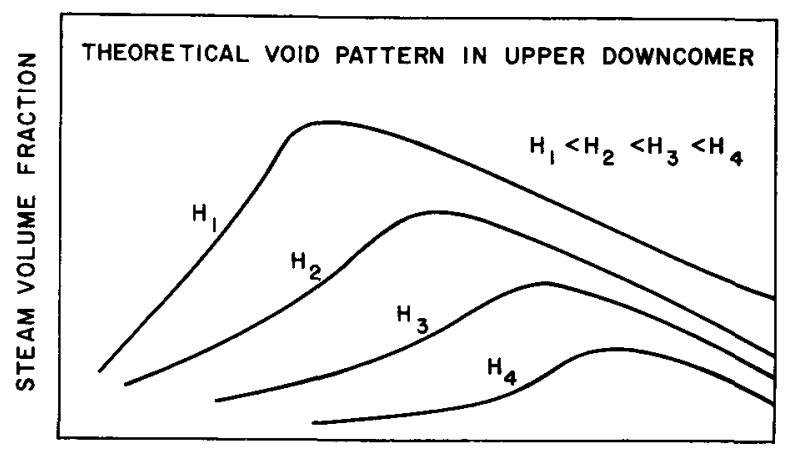

REACTOR POWER, MW

\section{Fig. 15}

Steam Volume Fraction as a Function of Reactor Power, Showing Void Pattern Expected in Upper Region of Downcomer

\section{$112-2607$}

The steam volume fraction data obtained from the upper and lower downcomer are shown in Figs. 12 and 13, respectively. At first glance, the data appear to be erratic, with excessive scatter. However, upon closer scrutiny, trends similar to those just described can be deduced which apparently substantiate the foregoing analysis. The major deterrent to establishing conclusive patterns is that the data were not taken over the entire power range at a fixed interface height. However, as shown in Fig. 12 at the lowest powers and lowest interface heights, the steam volume fraction in the upper section of the downcomer is maximum. As the interface height is raised and the power is increased, the steam volume fraction decreases in a manner similar to that predicted. In the lower region of the downcomer, the steam volume fraction is virtually zero under all conditions (see Fig. 13).

e. True Liquid Level. The difference between the level as indicated by the water column and the actual vapor-liquid interface level in the reactor is shown in Fig. 16. The height differential is a result of the steam voids present in the core, riser, and downcomer, and the "bubble bed" above the riser. The voids that are formed in the reactor core flow through the riser and are entrained in the downcomer, displacing an equal volume of water; this causes an increase in the mixture height. The water level above the riser is, in turn, further expanded by the vapor flowing through it; this creates a two-phase mixture or "bed." As can be seen in Fig. 16, the discrepancy between the two levels can be quite large. The height differential is primarily a function of the reactor power and increases as the power is increased. In the

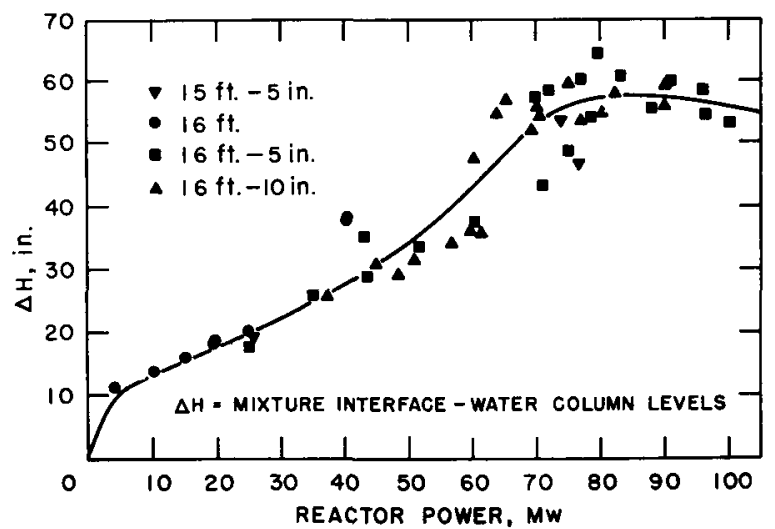

$112-2618$

Fig. 16. Height Differential Between Actual Interface Level and Water Column Level as a Function of Reactor Power and Various True Mixture Interface Levels. very high power range for which liquid carryover occurs, the height differential levels off and begins to decrease. This is a result of the sudden 
increase in subcooling and, hence, decrease in core and riser void content. The scatter of the data increases with power. This is probably due to the fact that the interface becomes more turbulent and less defined. The maximum error in establishing the average interface level was estimated to be 9 in.

f. Liquid Carryover. The three methods employed to determine the liquid carryover were described earlier. The results are com-

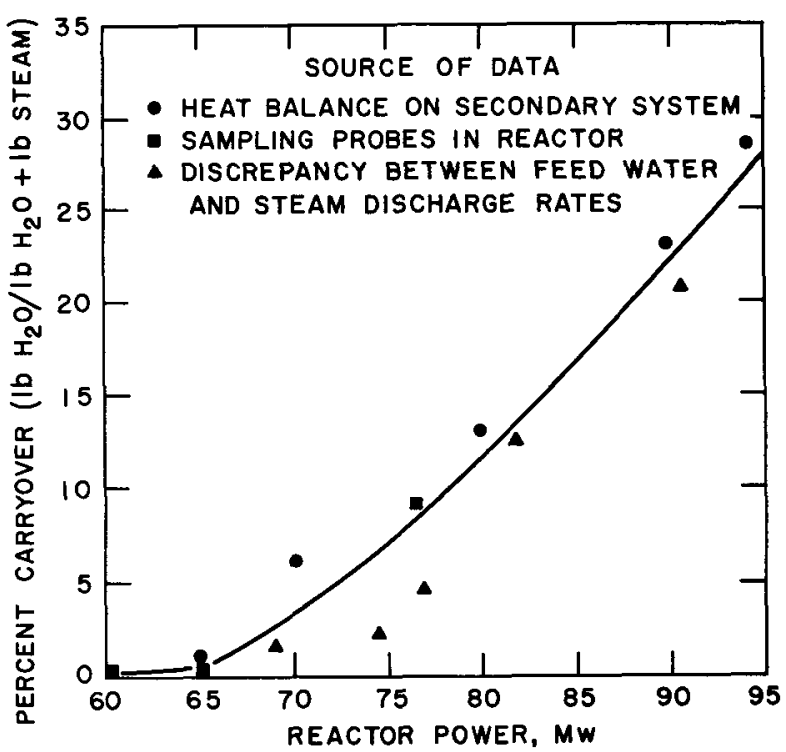

$112-2615$

Fig. 17. Per Cent Liquid Carryover as a Function of Reactor Power, Showing Comparison of Data Obtained from Three Sources pared in Fig. 17. They represent the first set of carryover measurements taken. Accordingly, these data are preliminary, since the true mixture interface levels were not determined at this time. The data do, however, serve to point up the agreement among the three techniques.

Only limited data were obtained from the sampling probes because of time considerations and termination of the project; however, some interesting trends are illus trated in Fig. 18, where the per cent liquid carryover is plotted as a function of the distance above the true interface. A family of curves is obtained for varying superficial vapor velocities; hence, it is readily apparent that carryover rates cannot be expressed in terms of superficial vapor velocities alone. The height of the steam dome must also

be specified. As the actual steam dome height decreases, the carryover increases rapidly.

Fig. 18

Per Cent Liquid Carryover as a Function of Distance Above Vapor Interface for Various Superficial Vapor Velocities

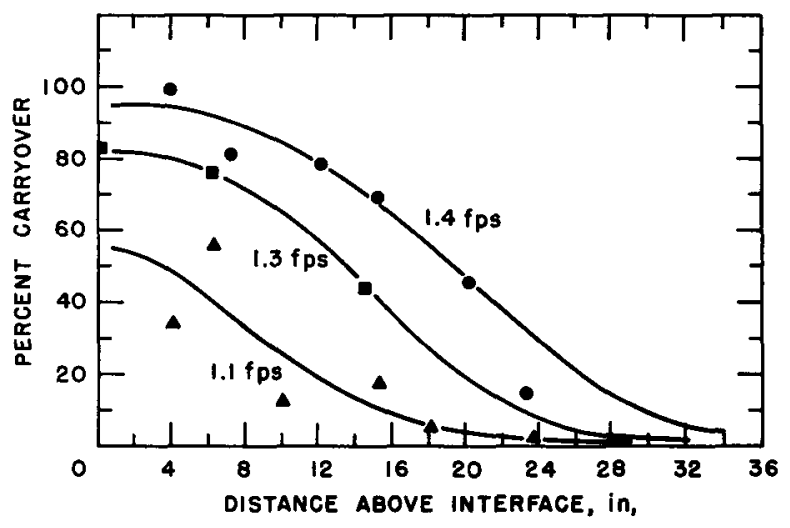

$112-2610$ 


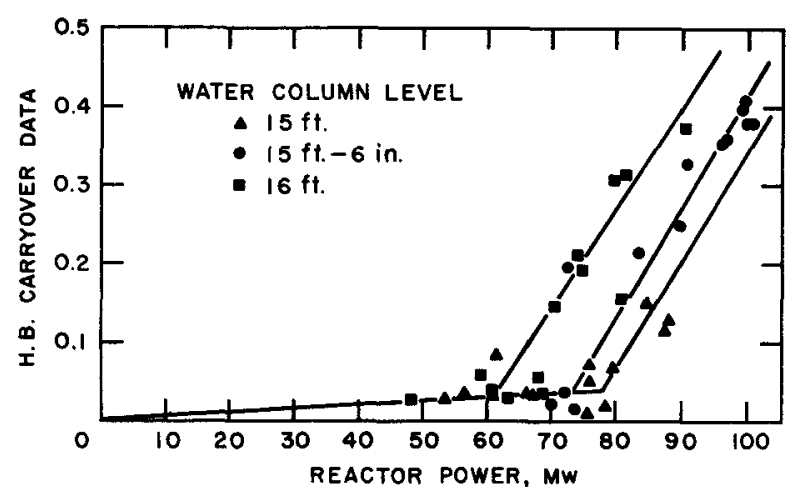

$112-2613$

Fig. 19. Liquid Carryover as a Function of Reactor Power and Various Water Column Levels (Data from Heat Balance on Primary Reboiler)
The liquid carryover data derived by the heat-balance technique are the most accurate and probably of greatest interest, since they represent the actual a mount of water carried ove $r$ into the turbine bypass line and the primary reboilers. As illustrated in Fig. 19, the initiation of carryover occurs at different power levels for different interface heights. At $60 \mathrm{Mw}$, the carryover starts at a superficial velocity of $1.1 \mathrm{ft} / \mathrm{sec}$ and with a steam dome height of 30 in. As the steam dome height is increased, the superficial vapor velocity required to initiate large amounts of carryover also increases.

A comparison of the data derived from the reactor with loop data obtained under static conditions (no fluid recirculation) shows that the magnitude of the carryover is larger for the reactor under the same conditions of vapor velocity and dome height. The amount of liquid carryover measured in the reactor was much larger than had been expected.

\section{B. Physics}

The results of the detailed physics studies that were made on $\mathrm{EBWR}$ are given in References 7 and 10. However, some pertinent physics data and parameters are presented below which corroborate the effect of the vapor-liquid separation process on reactor performance.

\section{Functions of Spike Fuel Assemblies}

The merits of and the reasons for the selection of the 100-Mwt core loading shown in Fig. 3 are described in detail in Reference 10 . One of the prime considerations which govern the arrangement of the spike fuel assemblies was to achieve as flat a power distribution as was possible. Other considerations included the use of boron-stainless steel strips to provide excess reactivity through the use of a burnable poison. However, owing to termination of the water reactor program, this latter objective was no longer of importance. Consequently, the primary functions of the strips attached to the spike fuel assemblies were: (1) to control the reactivity of the core, and (2) to provide the desired flexibility in effecting increases in reactivity as required. 
In planning the power operation of the reactor, the number of boron strips per spike was initially reduced to an average of 1.57 . With this configuration $\sim 5 \%$ reactivity was available for steam-void formation within the core.

\section{Core Parameters}

Prior to making power runs, the control rod system (with Zircaloy -2 followers) was calibrated. The results are plotted in Fig. 20.

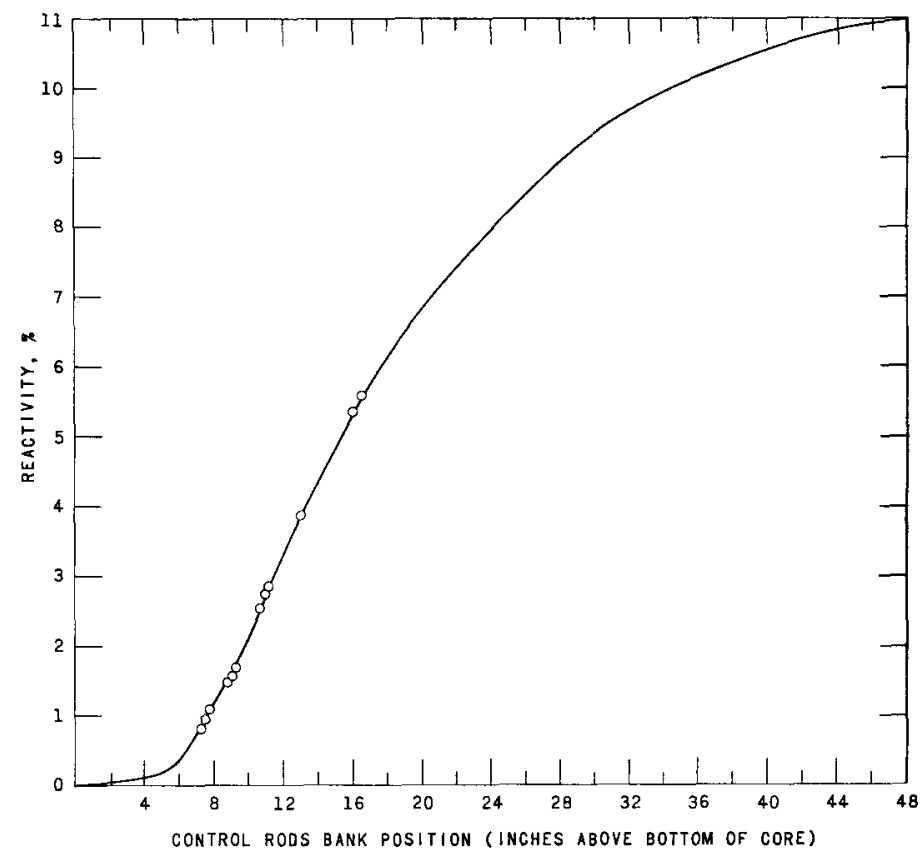

\section{$112-2629$}

Fig. 20. Bank Control Rod Calibration

In addition, some void coefficient measurements we re made with the aid of four void simulators installed in the fuel assemblies. Owing to dimensional limitations, the void simulators were confined to the thin, enriched plate assemblies. The measurements made with $\mathrm{H}_{3} \mathrm{BO}_{3}$ in the reactor were of particular interest. Extrapolation of these data indicated a negative void coefficient for concentrations as high as $10 \mathrm{gm} \mathrm{H}_{3} \mathrm{BO}_{3} /$ gal $\mathrm{H}_{2} \mathrm{O}$ in the core (2640 ppm).

a. Reactivity Distribution. A series of runs were then made over a power range from $0 \mathrm{Mw}$ to $60 \mathrm{Mw}$. Control of reactivity was achieved primarily by control rod movements for the operating range of $0-40 \mathrm{Mw}$; at $40 \mathrm{Mw}$ and with equilibrium xenon, the rods were all out. Above $40 \mathrm{Mw}$, control was achieved by reducing the $\mathrm{H}_{3} \mathrm{BO}_{3}$ concentration in the core water. At the $60-\mathrm{Mw}$ power level, $\sim 0.5 \% \rho$ was available to effect further increase in reactor power. 
In order to obtain powers greater than $65 \mathrm{Mw}$, it was necessary to remove additional strips from the spike elements. The core reactivity was increased $\sim 2 \%$ by reducing the number of boron strips to one strip per spike in the central ring of 28 spikes. This gave a total of $\sim 10.5 \%$ core reactivity after deducting $0.6 \%$ for burnup during these power runs. This allowed $\sim 1.5 \% \rho$ to increase the power above $65 \mathrm{Mw}$. The maximum reactivity that could be added was governed by the established shutdown criteria.

below:

A summary of reactivity distribution in the core is given

Reactivity required from cold to hot, zero voids Reactivity tied in steam voids for $60-\mathrm{Mw}$ operation Additional reactivity for operation beyond $60 \mathrm{Mw}$ Xenon poisoning at $80 \mathrm{Mw}$

Total reactivity

Control rod worth (cold reactor)

Reactivity worth of $\mathrm{H}_{3} \mathrm{BO}_{3}$ for $1 \mathrm{gm}$ of $\mathrm{H}_{3} \mathrm{BO}_{3} / \mathrm{gal} \mathrm{H}_{2} \mathrm{O}$ (264 ppm) $\sim 1 \% \rho$

$\sim 5 \% \rho$

$\sim 1.5 \% \rho$

$\sim 2.8 \% \rho$

$\sim 10.5 \% \rho$

$\sim 11 \% \rho$

$\sim 1.0 \% \rho$

b. Power Coefficient. The effect of steam carryunder and liquid carryover can readily be deduced from power coefficient measure-

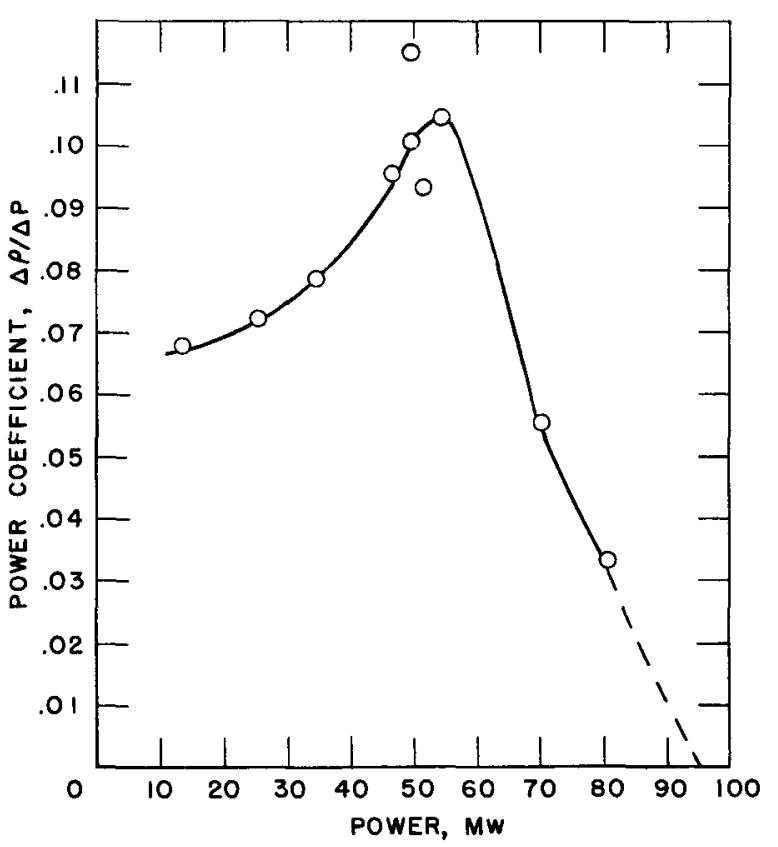

$112-2637$

Fig. 21. Power Coefficient vs. Reactor Power ments made over the power range from $0 \mathrm{Mw}$ to $80 \mathrm{Mw}$ for a fixed water column level. Power coefficients were obtained by determining the change in reactivity effected by control rod movements and by removal of boric acid. These data are shown in Fig. 21. In the lower power range, the power coefficient increases with increasing reactor power. It peaks at about $55 \mathrm{Mw}$, begins to decrease, and tends toward zero. The peak corresponds roughly to the power level at which liquid carryover commences and reactor subcooling begins to increase. Below $60 \mathrm{Mw}$, the carryunder phenomenon is predominant; this is reflected in the increasing power coefficient. Above $60 \mathrm{Mw}$, liquid carryover becomes the dominating factor and the power coefficient decreases. An extrapolation yields a zero value at $\sim 95 \mathrm{Mw}$. Moreover, the extrapolation indicates that above $\sim 95 \mathrm{Mw}$ the power would continue to increase without introducing additional reactivity. 
Such a sequence of events actually occurred in the EBWR, as evidenced by the data in Table III. With the rod bank at $34.4 \mathrm{in}$. and the center rod at $40 \mathrm{in}$., the reactor was at a power level of $67.7 \mathrm{Mw}$. The rod bank was raised to $38 \mathrm{in}$. and the power increased to $84.9 \mathrm{Mw}$. How ever, the reactor did not reach an equilibrium power level, but increased over a 10 -min interval to a level of $94.4 \mathrm{Mw}$. At this point the whole rod bank was reinserted to 36.7 in. After a series of rod manipulations an equilibrium power of $90.7 \mathrm{Mw}$ was achieved with the rod bank at $37.7 \mathrm{in}$. This rod bank position at $90.7 \mathrm{Mw}$ is lower than the corresponding position at $84.9 \mathrm{Mw}$. This unique behavior, attributed primarily to liquid carry over, was undoubtedly aided, to some extent, by the expulsion of boric acid from the reactor through the mechanism of carryover.

Table III

CONTROL ROD POSITIONS VS. POWER (Boric Acid Content $=1 \mathrm{gm} / \mathrm{gal}$ )

\begin{tabular}{|c|c|c|c|}
\hline \multirow[b]{2}{*}{ Time } & \multicolumn{2}{|c|}{$\begin{array}{c}\text { Rod Positions, } \\
\text { in. } \\
\end{array}$} & \multirow{2}{*}{$\begin{array}{c}\text { Power, } \\
\text { Mwt }\end{array}$} \\
\hline & $1-8$ & Center Rod & \\
\hline 1245 & 34.4 & 40 & 67.7 \\
\hline 1338 & 38 & 40 & 84.9 \\
\hline 1348 & 38 & 40 & 94.4 \\
\hline 1404 & 36.7 & 36.7 & 82.0 \\
\hline 1430 & 36.7 & 36.7 & 80.6 \\
\hline 1510 & 37.7 & 37.7 & 90.7 \\
\hline
\end{tabular}

The same reactor behavior pattern can be seen in the reactivity versus power level plot shown in Fig. 22. Below $60 \mathrm{Mw}$, a singlevalued functional relationship exists between the two parameters. The branching of the curve at $60 \mathrm{Mw}$ is a result of the carryover mechanism It is apparent that the maximum power that could be attained (all rods out and boric acid concentration $<40 \mathrm{ppm}$ ) was governed directly by the liquid level. For a water column level of $14 \mathrm{ft} 10$ in., the maximum power level was $72 \mathrm{Mw}$. When the water level was raised to $16 \mathrm{ft}$, the design power level of $100 \mathrm{Mwt}$ was readily achieved, with $\sim 065 \% \rho$ remaining.

c. Void Coefficient of Reactivity. The void coefficient $\Delta \mathrm{k} / \Delta \mathrm{V}$ of the core was computed to be 0.195 for a change of $0-10 \%$ in the average void content of the core. This value was obtained from rough preliminary calculations. Detailed calculations, which will take into consideration the increased void content, are in progress. Based 
on this preliminary analysis, an estimate of the average void content in the core was made as a function of power, and is shown in Fig. 23. Included are the average void fractions computed from thermal hydrodynamic analyses by use of the measured reactor subcoolings. As can be seen, the average core coolant void fraction derived from physics and thermal hydraulic considerations are in fair agreement.

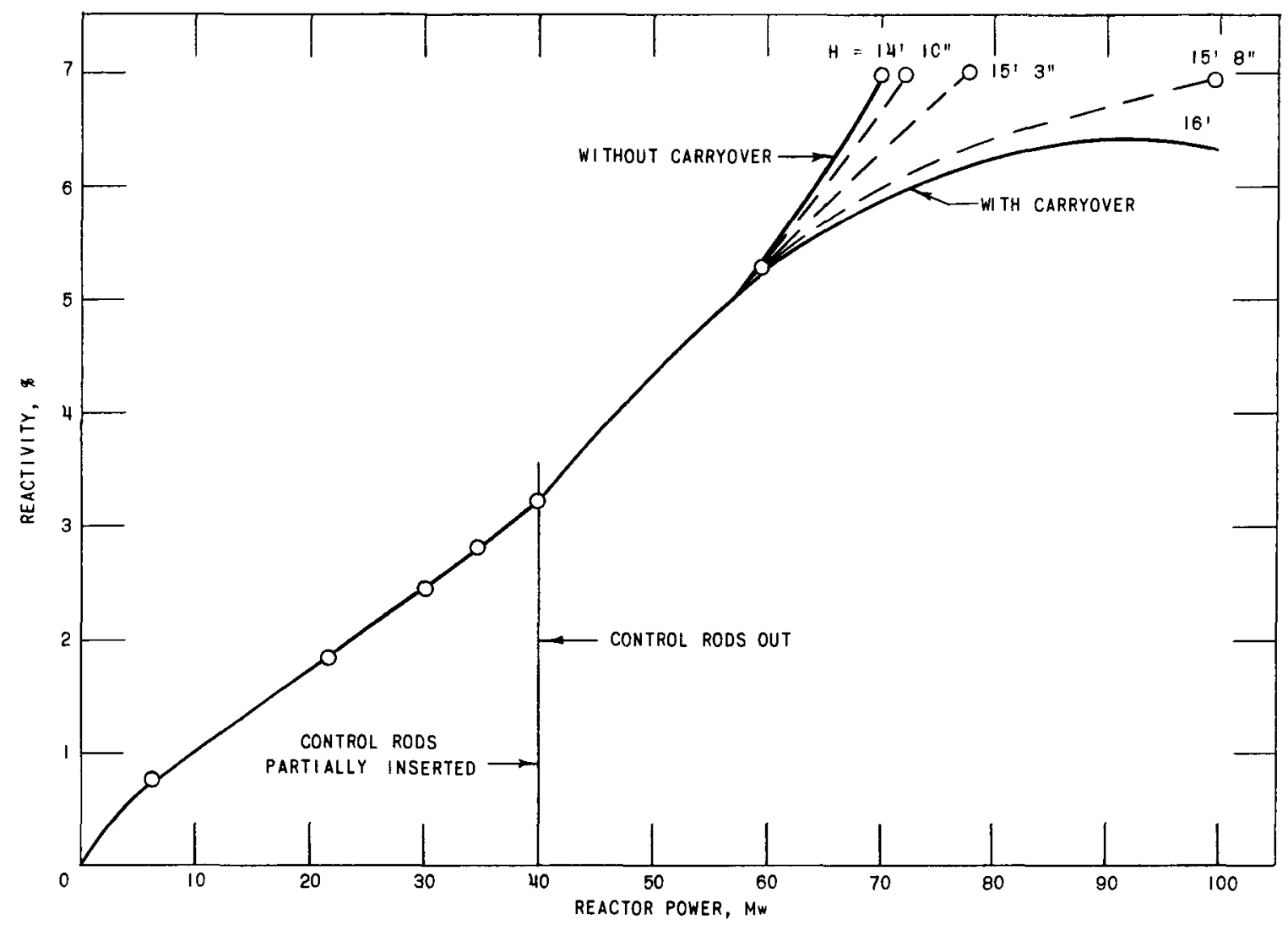

$112-2641$

Fig. 22. Reactivity vs. Reactor Power

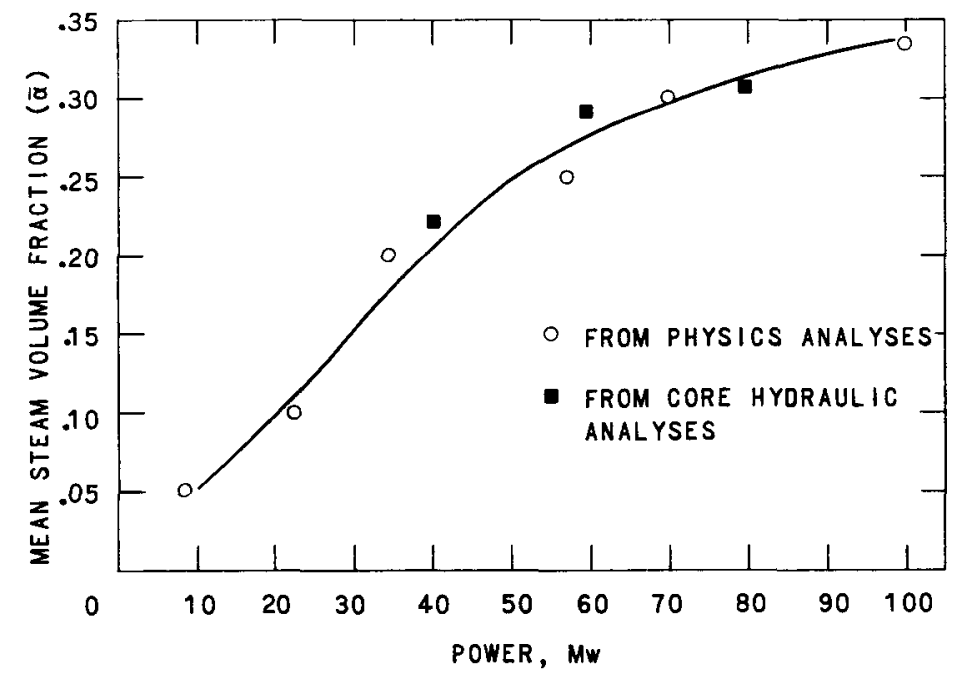

Fig. 23

Mean Core Steam Volume Fraction vs. Reactor Power 
d. Neutron-flux Distributions. A method was developed for, and used in, the EBWR for characterization of the neutron flux as a function of location in the core, reactor power, and reactor control parameters. Bare and cadmium-covered cobalt foils were introduced and accurately positioned for irradiation in selected locations in the core. After irradiation, they were removed without affecting reactor operation.

The activation detector foils were prepared as small spheres ground to precision tolerances. This shape and close dimensional control eliminated individual weighings and obliquity effects in the isotropic flux, and greatly simplified automatic analysis.

The activated foils were analyzed with conventional instrumentation, and the the rmal and resonance neutron-flux components were calculated. Figures 24 and 25 show typical thermal neutron-flux distribution isogram plots constructed from several axial plots to show both axial and radial distributions in one quadrant of the core. The left margin of each plot represents the center line of the core.

The power level for both isogram plots was $40 \mathrm{Mw}$. The boric acid concentrations were $25 \mathrm{ppm}$ and $1200 \mathrm{ppm}$ for Figs. 24 and 25. respectively. It will be noted that the peak power in the presence of soluble poison control is considerably lower [highest isogram is $2.6 \times 10^{13} \mathrm{n} /$ $\left.\left(\mathrm{cm}^{2}\right)(\mathrm{sec})\right]$ than the peak power in the absence of a significant concentration of soluble poison [highest isogram is $\left.3.75 \times 10^{13} \mathrm{n} /\left(\mathrm{cm}^{2}\right)(\mathrm{sec})\right]$. The effec tive core size is much larger and better distributed in the presence of soluble poison shim control and should result in a more uniform burnup of the fuel throughout the core.

Isogram plots were also prepared to show the effer $t$ of reactor power level on thermal and resonance neutron-flux distribution, and to show the effect of operation with the control rods in an unusual non-banked configuration (see Reference 8).

\section{Specific Observations}

\section{Fuel Assemblies}

The original EBWR core contained 114 fuel assemblies surrounded by 32 aluminum dummy fuel assemblies to fill the grid plate. This core remained essentially undisturbed for about $3 \mathrm{yr}$ in the reactor vessel. During this time, deposits varying in thickness (up to $0.008 \mathrm{ir}$ ) had built up on the fuel-plate surfaces. Attempts to remove the deposit proved not practical. Analys is of sample scrapings revealed a composition of $67 \mathrm{w} / 0$ boehmite $\left(\mathrm{Al}_{2} \mathrm{O}_{3} \cdot \mathrm{H}_{2} \mathrm{O}\right), 25 \mathrm{w} / \mathrm{o}$ nickel, and $8 \mathrm{w} / \mathrm{o}$ iron.

Consequently, the aluminum dummy fuel as semblies were adjudged the principal source of the scale. The exact mechanism of deposition has 


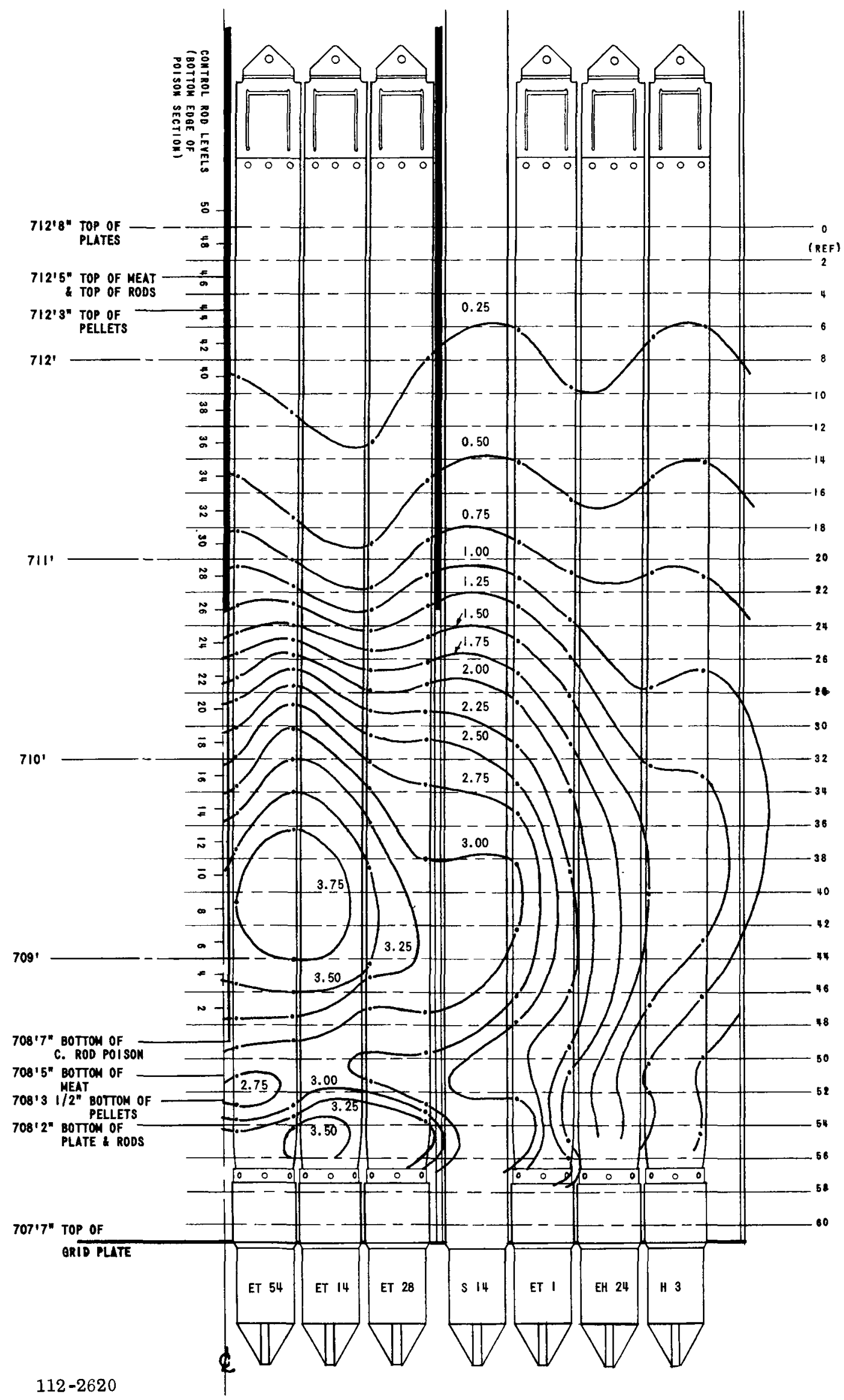

Fig. 24. Thermal Neutron Flux Isogram Plot for Reactor Power of $40 \mathrm{Mwt}$ and Soluble Poison Concentration of 25 ppm Boric Acid 


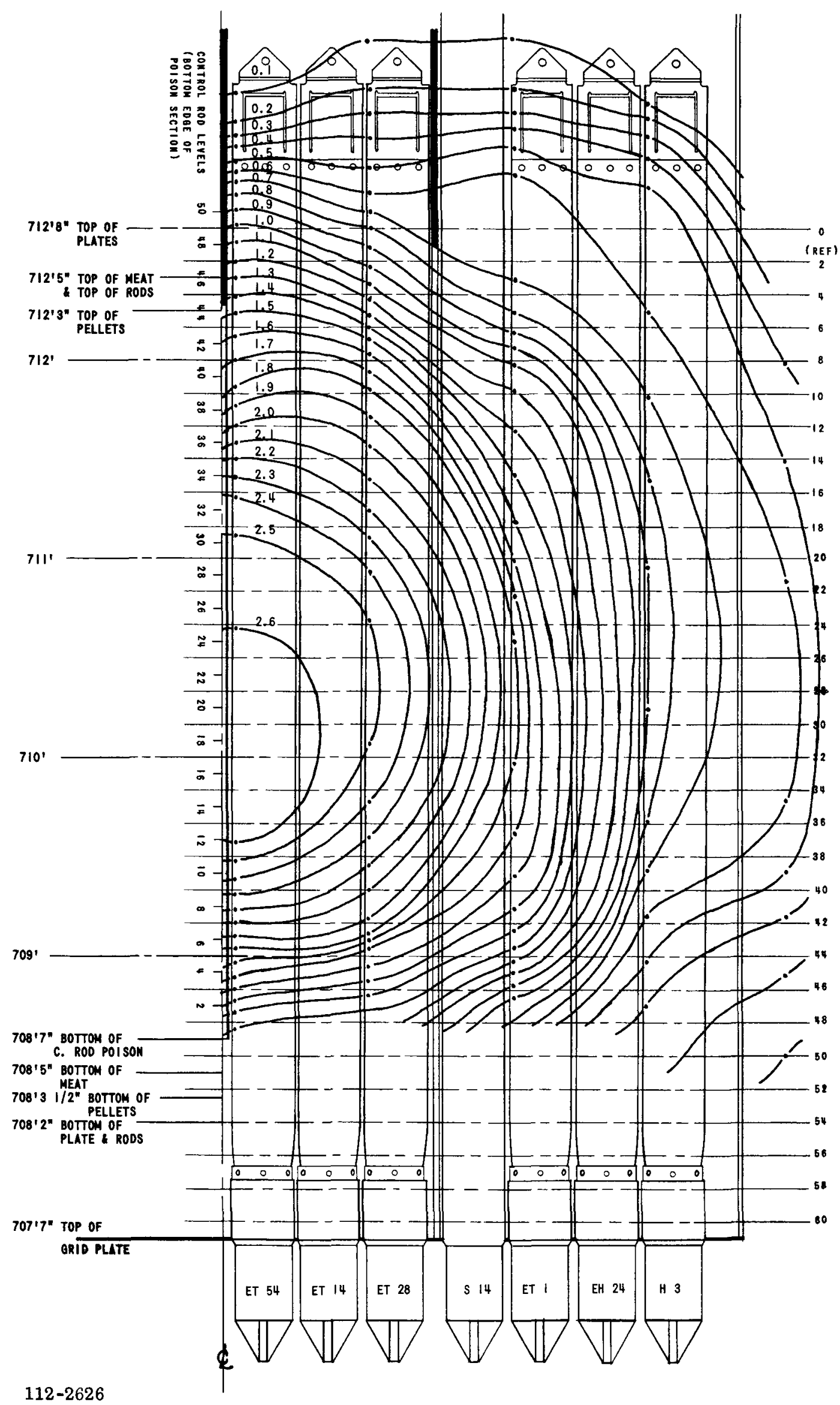

Fig. 25. Thermal Neutron Flux Isogram Plot for Reactor Power of $40 \mathrm{Mwt}$ and Soluble Poison Concentration of 1200 ppm Boric Acid 
not been resolved; however, it is fairly well established that the mass transfer is from the dummy fuel boxes to the coolant and then to the active fuel plates, primarily on the boiling areas of the plate surfaces. All aluminum dummy fuel assemblies were removed from the core in order to provide space for the additional spike fuel assemblies of the high-power runs.

This scale was a matter of deep concern during operation at elevated powers. The existing scale on the fuel plates represented a barrier to effective heat transfer. The thermal conductivity of the scale had been estimated to be less than $1 \mathrm{Btu} /(\mathrm{hr})\left(\mathrm{ft}^{2}\right)\left({ }^{\circ} \mathrm{F} / \mathrm{ft}\right)$. At elevated powers, the scale could promote a central fuel temperature of $\sim 1125^{\circ} \mathrm{F}$. At this temperature, the creep strength of the uranium alloy would be reduced, and the fission gas trapped in the fuel plates could cause considerable swelling. It was feared that some fuel plates would eventually rupture.

Initial evidence of fuel growth was observed upon completion of the 85-Mwt power level phase of the program. Cursory examination of the plate assemblies (under the core water) revealed that the side plates were slightly distorted, with some loss of the scale. There were no detectable physical defects in the fuel plates.

After shutdown from $100 \mathrm{Mw}$, some plate and spike fuel assemblies were removed for visual examination. There were no perceptible changes in the spike assemblies; however, definite changes were observed in the plate-type assemblies. The perforated side plates had buckled about $\frac{i}{16}$ in. between spot welds (in the horizontal position and not between fuel plates). Maximum deformation occurred in the region of highest flux and diminished toward the ends of the fuel plates.

The following comments are subject to confirmation by current destructive and nondestructive tests with these assemblies. The buckling may be attributed to the difference in expansion coefficients of the Zircaloyclad metallic fuel and the Zircaloy side plates. However, the fuel plates did not buckle because the clad was bonded to the fuel. During the highpower runs, the side plates may have exceeded their elastic limit and as a consequence, buckled as the metallic fuel plate contracted after reactor shutdown. With respect to the loss of some scale: evidently at some power above $60 \mathrm{Mwt}$, the scale was subjected to a shearing stress induced by expansion of the fuel plates. Undoubtedly, the descaling process improved heat transfer between fuel plates and the primary coolant. At this time, it can only be speculated that a redistributed deposition of the spallings would have occurred with continued operation. 


\section{Radiation Levels}

During reactor operation and/or subsequent shutdown, authorized personnel were permitted to enter the Containment Shell and the Reboiler Building for purposes of performing experiments or maintenance on system components. The following sections describe briefly the radiation levels that were encountered, the contributing factors, and the corrective measures that were taken.

a. Transport of Corrosion Products. Scale spalling from the fuel plates presented some radiation problems, particularly in the subreactor room. The settling and accumulation of this scale in control rod rack housings and flanged appendages for the original forcedcirculation nozzles created radiation levels up to $20 \mathrm{r} / \mathrm{hr}$ at contact. Blow down of the se nozzles (to a dump tank) effected a reduction in surface radiation to $3-5 \mathrm{r} / \mathrm{hr}$.

At power levels above $65 \mathrm{Mw}$, at which water carryover with the steam was encountered, fine particles of scale were entrained with the water. These particles did not plate out on any surfaces external to the reactor vessel, but were eventually collected in the full-flow condensate filters. Radiation levels external to the filter vessels normally are $10-15 \mathrm{mr} / \mathrm{hr}$, but with carryover the levels increased to $20 \mathrm{r} / \mathrm{hr}$. Irradiated particles of scale were also collected in the reactor waterpurification filters and resin beds. These vessels are shielded with lead ( $4 \mathrm{in.}$ thick); therefore, no significant radiation levels were encountered.

A fine coating or iron oxide (rust colored) was deposited on all the surfaces that were contacted by the primary fluid. It is believed that the bulk of the iron came from the carbon steel condenser shell and some of the carbon steel piping.

b. Plant Activities. Radiation levels in the Containment Shell and in the Reboiler Building can be attributed primarily to $\mathrm{N}^{16}$ (half life $=7.4 \mathrm{sec}$ ) except for liquid carryover of ir radiated corrosion products. The amount of liquid carryover is a function of the reactor power and is especially sensitive to interface level in the reactor vessel. With no carryover, radiation levels in the Containment Shell were essentially the same as was reported for $20-\mathrm{Mw}$ operation.(1) This was true whether the reactor was operated at $20 \mathrm{Mw}$ or at $80 \mathrm{Mw}$. The original 20-Mw plant and the reboiler plant were operated in parallel; steam in excess of $20 \mathrm{Mw}$ was shunted to the reboilers. Since $\mathrm{N}^{16}$ is the primary contributor of activity, and decays through several half-lives before it re-enters the containment shell, it retains only very minute amounts of activity. Table IV lists typical radiation levels registered in the Contalr. ment Shell. 
Table IV

RADIATION LEVELS IN CONTAINMENT SHELL $(\mathrm{mr} / \mathrm{hr})$

\begin{tabular}{|c|c|c|c|}
\hline \multirow[b]{2}{*}{ Monitor Location } & \multicolumn{3}{|c|}{ Power Distribution } \\
\hline & $\begin{array}{l}22 \text { Mwt to Turbine } \\
55 \mathrm{Mwt} \text { to Reboilers } \\
(10 / 31 / 62)\end{array}$ & $\begin{array}{c}15 \mathrm{Mwt} \text { through } \\
\text { Turbine Bypass } \\
75 \mathrm{Mwt} \text { to Reboilers } \\
(11 / 1 / 62)\end{array}$ & $\begin{array}{c}3.3 \mathrm{Mwt} \text { through } \\
\text { Turbine Bypass } \\
53 \mathrm{Mwt} \text { to Reboilers } \\
(11 / 1 / 62)\end{array}$ \\
\hline Turbine & 46 & 10 & 6 \\
\hline Plant Main Floor Area & 0 & 0 & 0 \\
\hline Steam Dryer & 1100 & 1100 & 400 \\
\hline Air Ejector & 1700 & 2000 & 80 \\
\hline Condenser Hotwell & 110 & 280 & 50 \\
\hline Plant Air Exhaust Duct & 70 & 50 & 30 \\
\hline Air Ejector Gas Filter & 100 & 70 & 40 \\
\hline
\end{tabular}

One unexpected source of radiation was detected in the subreactor room. An intense neutron beam was emitted from each of the two, large, forced-circulation piping nozzles that extend through the shielding beneath the reactor. Neutron streaming which occurred in the annuli between the 12 -in. pipes and their respective $20-i n$. sleeves was attributed to enlargement of the initial 4-ft-diameter core to a 5-ft-diameter core. As a consequence: ( 1 ) the core was in closer proximity to the nozzles, and (2) the shielding afforded by the water in the core downcomer was diminished. Further neutron streaming was precluded by filling the annuli with water to a height that extended $\sim 1 \mathrm{ft}$ into the biological shield.

Figure 26 shows the radiation levels registered at various locations in the Reboiler Building. The primary system components are enclosed by a concrete wall ( $1 \mathrm{ft}$ thick). The maximum radiation level at the outer surface was $15 \mathrm{mr} / \mathrm{hr}$.

Upon termination of the experimental program, the turbine was dismantled for routine inspection. The maximum radiation level on any surface was $1 \mathrm{mr} / \mathrm{hr}$ at contact. The inside surfaces of the turbine had been plated with 0.005 in. of nickel by the Kanigen process. Most of this plating had eroded, especially in areas where steam velocity was highest. Otherwise the turbine appeared to be in good condition.

c. Fission Gas Release. As a point of interest, fission gas release due to fuel-element failure has not been experienced throughout the history of EBWR operation. The fission gases that were detected (see Fig. 27) are attributed to fission of tramp uranium that adhered to the plate surfaces during fabrication. Minute amounts of $\mathrm{Xe}^{133}$ were also detected but are not shown in the figure. 


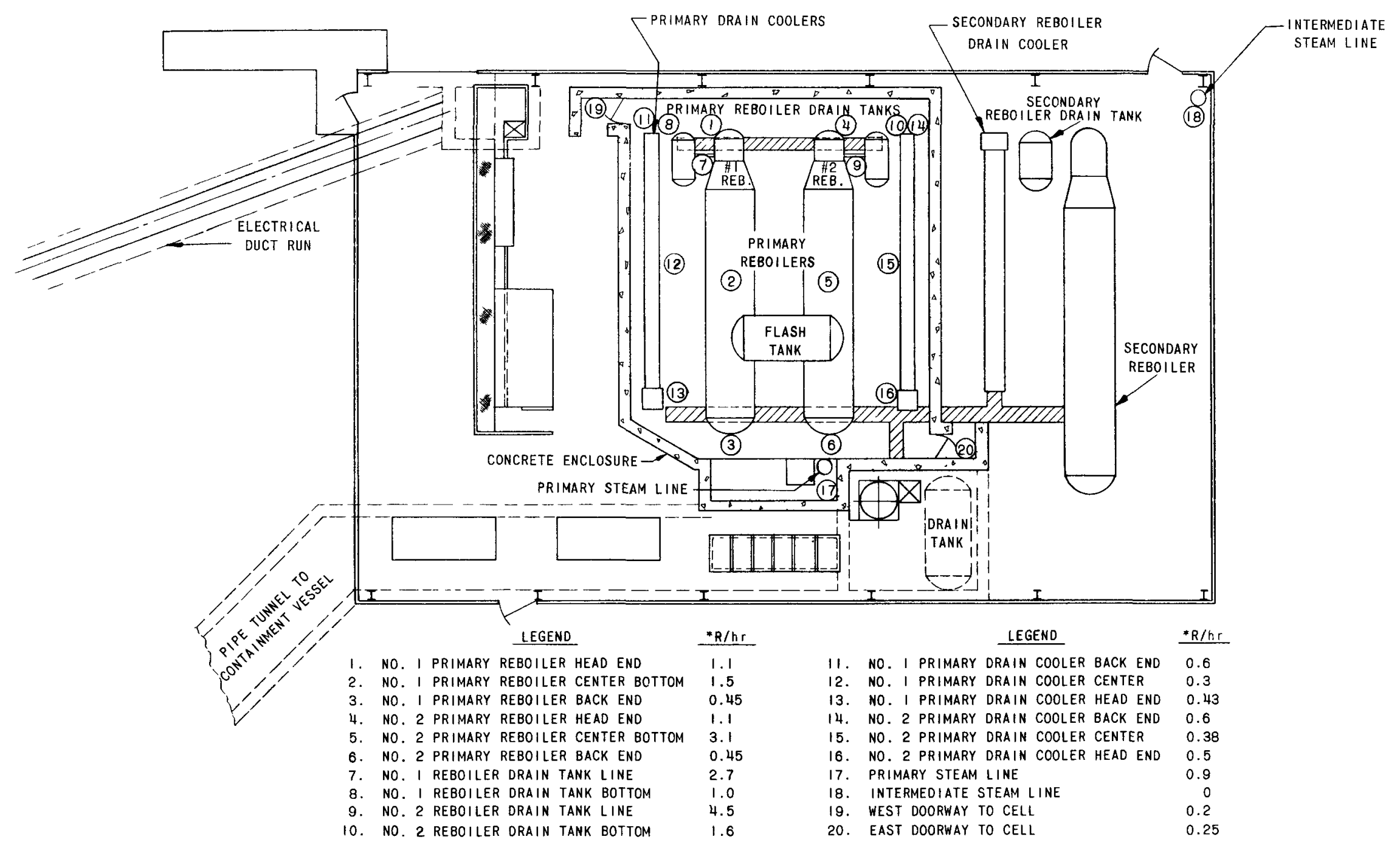

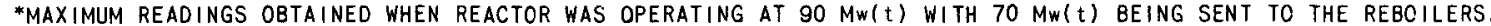
READINGS WERE 2" FROM SURFACES EXCEPT IN DOORWAYS WHERE A GENERAL BACKGROUND LEVEL IS GIVEN.

Fig. 26. Location of Radiation Measurement Points in Reboiler Building 


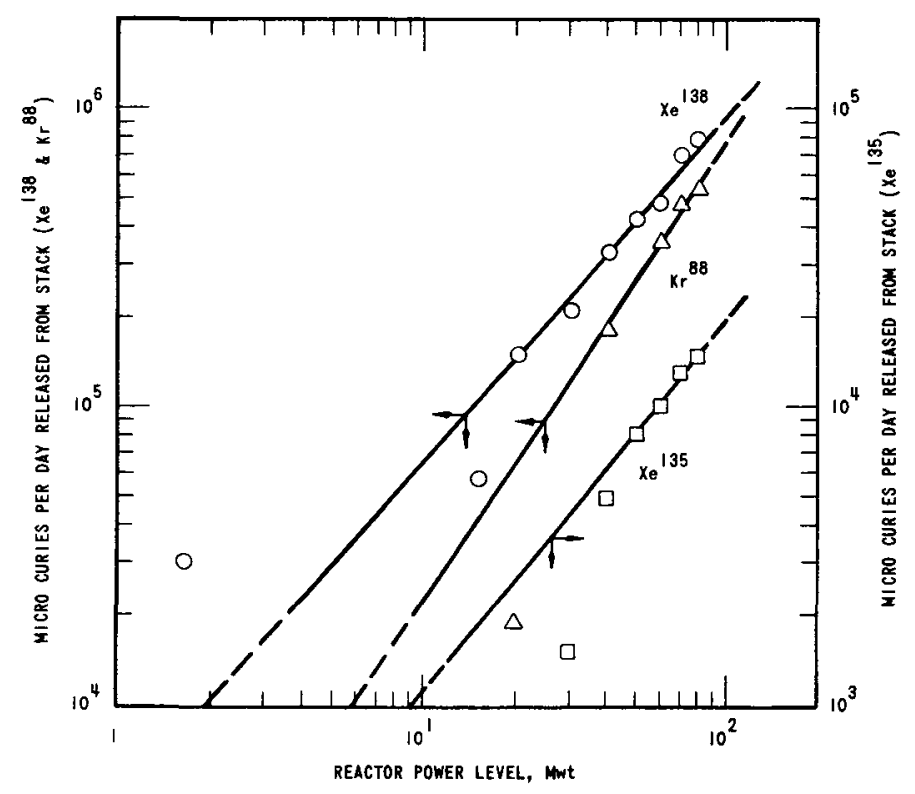

$112-2622$

Fig. 27. EBWR Fission Gas Release vs. Reactor Power

Gas samples from the exhaust stack and, also, downstream of the air ejector were filtered and drawn into evacuated collectors.

Two methods of gas analysis were employed. Briefly, a chemical method was used for gases decaying into a radioactive particulate daughter. The activity of the daughter is determined and, from equilibrium information, the activity of the gaseous parent can be calculated. This method is satisfactory for $\mathrm{Xe}^{138}$ and $\mathrm{Kr}^{88}$. The second method involved the use of a single-channel, pulse-height analyzer. This method is satisfactory for determining the longer half-life products, such as $\mathrm{Xe}^{135}$ and $\mathrm{Xe}^{133}$. $\mathrm{A}$ detailed description of both methods is given in Reference 3.

\section{On the Use of Soluble Poisons (Boric Acid)}

From time to time, questions are raised about the use of boric acid for augmentive control in an operating reactor. The term: "hideout" is used occasionally. Other questions pertain to improper or incomplete mixing, or to operational difficulties such as crystallization and reliability of monitoring the boric acid concentration.

a. Hideout. The EBWR has had many months of operation with boric acid in the reactor at concentrations in general not exceeding $5 \mathrm{gm} / \mathrm{gal}$. Hideout has not been experienced. If it does exist, the quantities must be very minute and do not present a problem. Saturated steam leaving the reactor (assuming no water carryover) carries a boric acid concentration of one part in seventeen of that present in the reactor water. 
This is due to volatilization and not carryover. This means that the concentration in the condenser hotwell is approximately $6 \%$ of the concentration in the reactor vessel. This presents no problem, since equilibrium is established within a few minutes during reactor operation. However, where large amounts of water are carried over with the steam, entrained boric acid is carried over with the water. Eor example, during a power run at $91.5 \mathrm{Mw}$, the boric acid concentration in the hotwell was $186 \mathrm{ppm}$, whereas it was $422 \mathrm{ppm}$ in the reactor vessel. Without carryover and with a concentration of $422 \mathrm{ppm}$ in the reactor, the normal concentration in the hotwell would be about 25 ppm.

b. Dilution. During cold critical experiments, the boric acid concentration in the reactor vessel was easily varied by dilution. This simply involved adding clean water, mixing, and then draining the vessel to a predetermined level.

Dilution of the poison by the addition of clean water is relatively slow. As far as reactivity hold-down is concerned, boric acid presents no real hazard with one possible exception. Mixture of boric acid solution with the reactor water may be a problem when there is no natural convection. This will not prevail during operation or if sufficient core decay heat is available to induce natural circulation.

To obtain good mixing in the EBWR, air was bubbled through the reactor water for $15 \mathrm{~min}$ after the addition of boric acid (with the vessel pressure at atmospheric conditions). There was no indication of crystallization or settling out of the crystals once a homogeneous solution was obtained, even with concentrations up to $2,640 \mathrm{ppm}$.

c. Removal. During reactor operation, removal of the soluble poison was accomplished with the reactor water-purification system in conjunction with an anion-resin-bed ion exchanger. Water was pumped from the reactor at about $8 \mathrm{gpm}$, cooled, and passed through the anion resin bed (of 9-cu ft volume). Subsequently, the water was circulated through a standard mixed-bed ion exchanger ( $1.2 \mathrm{cu} f t$ of resin) to insure neutral water, reheated, and pumped back to the reactor. In this manner, the boric acid concentration in the reactor was reduced by a factor of two in about 5 to $6 \mathrm{hr}$.

d. Monitoring. Two primary monitoring methods were used to determine the boric acid concentration: (1) continuous monitoring of water flowing through a sample cell in the purification system, and (2) bi-hourly determinations in an apparatus designed for individual samples. Both methods are based on neutron absorption by the poison. A chemical titration method was used periodically as a check on the monitors. 
The neutron-absorption method is based on a high cross section of boron-10 for thermal-neutron capture. The apparatus consists of a plutonium-beryllium source $\left(10^{7} \mathrm{n} / \mathrm{sec}\right)$ and a detector arranged in a cell of suitable geometry. Reactor water circulates continuously through the cell. The concentration of boron determines the attenuation of the thermal-neutron flux between the source and the detector.

In EBWR, a signal from the neutron ionization detector chamber was measured with a vibrating-reed electrometer in a circuit incorporating feedback stabilization and control. A continuous recorder in the control room indicated the boric acid concentration.

D. Reactor Transfer Function Measurements

\section{Methods}

EBWR stability was determined by measuring the reactor transfer function at selected power levels and extrapolating the results of these measurements to obtain an upper limit for stable operation. Measurements were made at 10,20,40,60, and $71 \mathrm{Mw}$. The data indicated a maximum stable power of $120 \mathrm{Mw}$.

a. Sinusoidal Reactivity Input. The power transfer function was obtained by exciting the reactor with a sinusoidal reactivity input, and measuring the amplitude and phase shift of the neutron-flux output with respect to the control rod input at selected frequencies. The inherent noise of the boiling process tended to reduce the accuracy of the measurements; therefore, noise-rejection techniques based on crosscorrelation were used.

Cross-correlation of the control rod position (input) and neutron flux (output) allowed the reactor transfer function to be calculated with the desired degree of accuracy. Two methods were employed to compute the cross-correlation. One method used an analog computer to multiply the output signal by sin $\omega t$ and $\cos \omega t$, and to integrate the resulting products; the resulting vector is the magnitude and phase angle of the output signal. The other method employed a digital-recording system which converted the analog input and output signals to digital data, and stored these data on a magnetic tape. The magnetic tape was then used to enter the experimental data into an IBM-704 computer. The digitalcomputer program was written to compute the cross-correlation of the input-output signals, and the amplitude and phase shift of the reactor transfer function. 
The measured power transfer functions are shown in Fig. 28. The gain is given by

$$
20 \log _{10}\left[\left(\Delta \mathrm{n} / \mathrm{n}_{0}\right) /(\Delta \mathrm{k} / \beta)\right] \text {, }
$$

where

$$
\begin{aligned}
\Delta \mathrm{n} & =\text { peak value of sinusoidal component of neutron flux } \\
\mathrm{n}_{0} & =\text { average neutron flux } \\
\Delta \mathrm{k} & =\text { reactivity } \\
\beta & =\text { delayed-neutron fraction. }
\end{aligned}
$$

The absolute gain of the power transfer function was not measured directly because of the uncertainty in control rod worth in the presence of voids. Therefore, the data of Fig. 28 were normalized to the zero-power transfer function by providing a best fit to the three highest frequency points. This type of normalization is valid provided the feedback is negligible at the se frequencies.

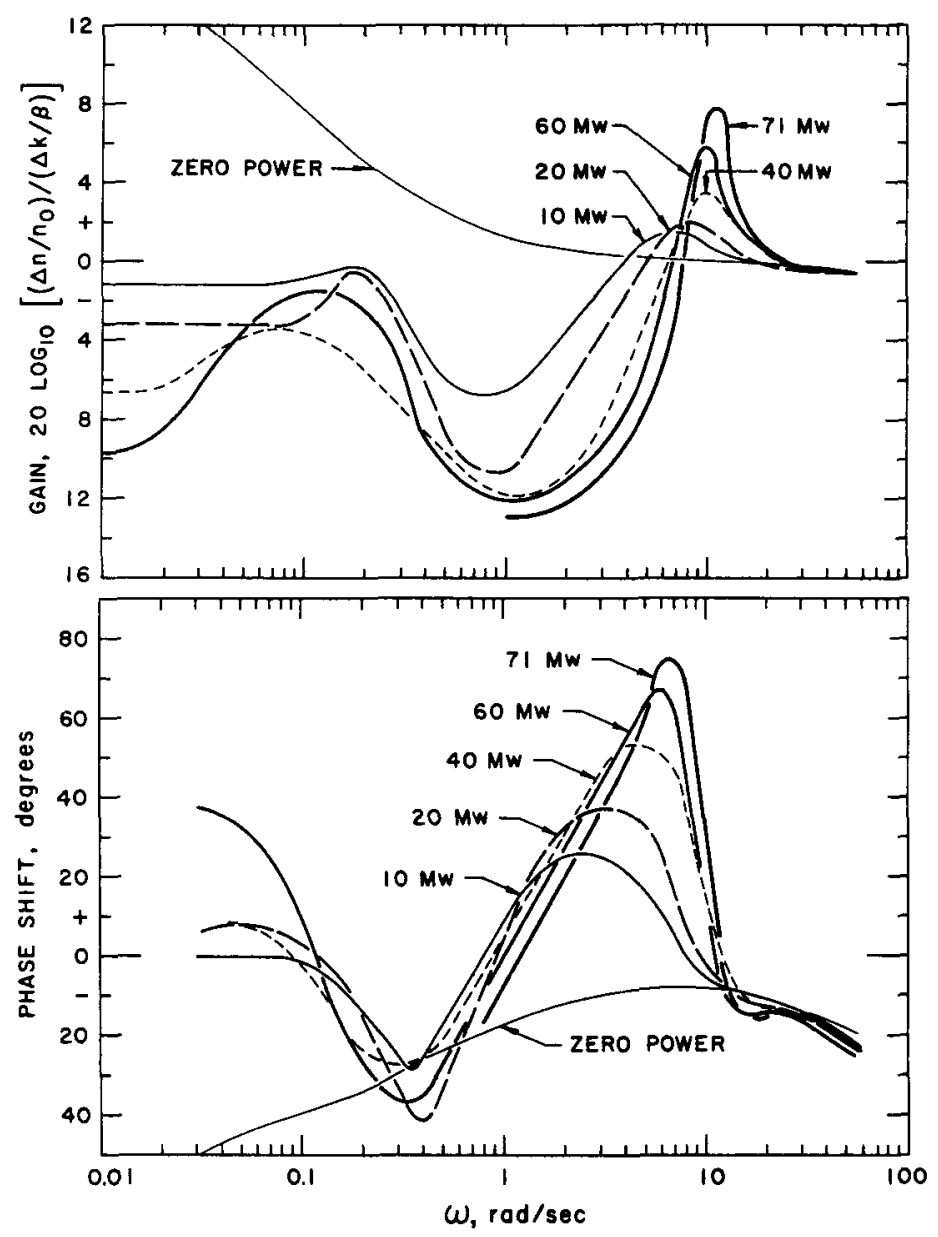

\section{$112-2647$}

Fig. 28. Reactor Transfer Functions 
Reactor stability was examined by calculating the closed loop gain and phase margin. The block diagram of the reactor with feedback is shown in Fig. 29. The power transfer function is given by

$$
P=\frac{G}{1+G H}=\frac{\text { Flux output }}{\text { Reactivity input }} \text {, }
$$

where $\mathrm{P}, \mathrm{G}$, and $\mathrm{H}$ are complex quantities and functions of frequency. Instability exists when $G H=-1$, or when $|G H|=1$ with the simultaneous condition of $\angle \mathrm{GH}=-180^{\circ}$. The terms GH can be extracted from the experimental data by substituting $G$ and $P$ in the equation

$$
\mathrm{GH}=\frac{\mathrm{G}}{\mathrm{P}}-1
$$

The zero-power reactor transfer function $G$ is measured at very low power prior to the onset of boiling.

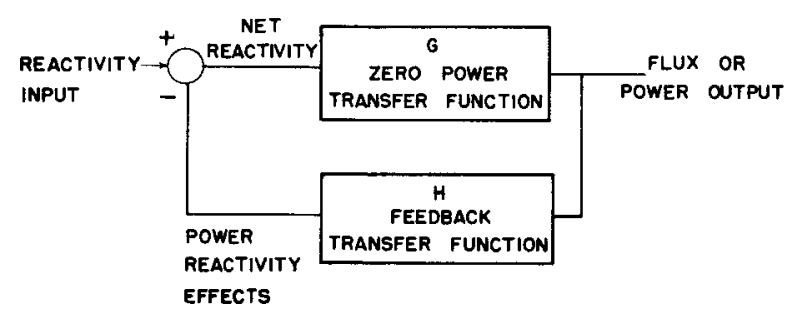

Fig. 29

Block Diagram of Reactor with Feedback

\section{$112-2640$}

A plot of $|\mathrm{GH}|$ at $-180^{\circ}$ and of phase margin as function of power is shown in Fig. 30. Phase margin is the additional phase shift that must be added to the $\angle \mathrm{GH}$ to obtain a total phase shift of $-180^{\circ}$ at $|\mathrm{GH}|=1$. Extrapolation of the gain and phase margins indicates a maximum stable power of $120 \mathrm{Mwt}$ for the EBWR.

The maximum power achieved with all control rods withdrawn and with $\sim 2 \%$ carryover was $60 \mathrm{Mwt}$ (before destripping $\sim 2 \%$ worth). To increase power above $60 \mathrm{Mwt}$, the mode of reactor operation was modified and operation up to $100 \mathrm{Mwt}$ was achieved by increasing feedwater flow to the reactor. This increased the subcooling which, in turn, provided additional reactivity.

b. Autocorrelation. Operation at the higher powers required all control rods to be withdrawn; consequently, the center rod was not available for transfer function measurements. At powers above $70.7 \mathrm{Mwt}$, only noise data were taken; autocorrelation functions and power-density spectrums were computed. 

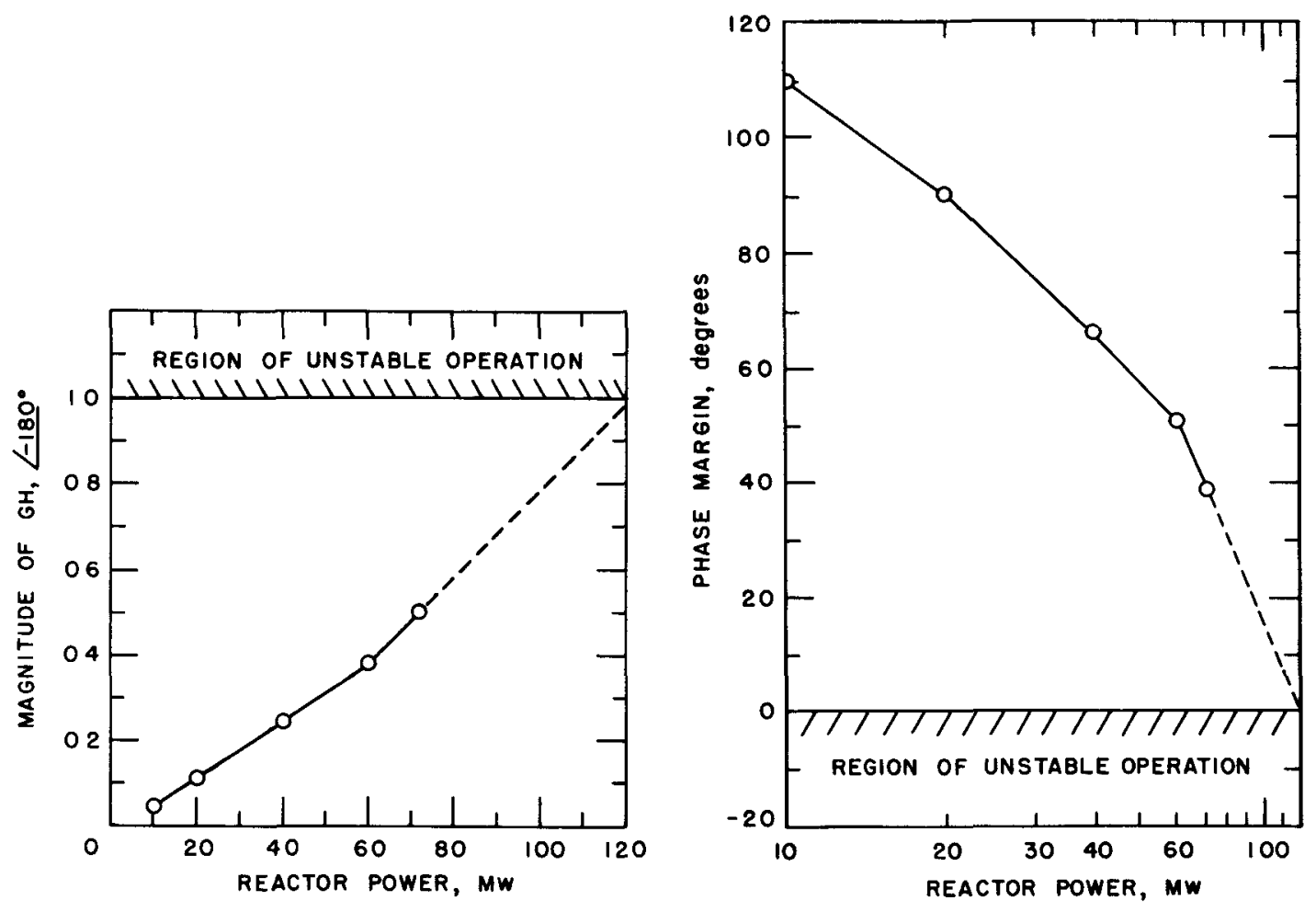

$112-2642$

Fig. 30. Reactor Gain and Phase Stability

Figure 31 shows a time record of the neutron flux at $100 \mathrm{Mwt}$. The autocorrelation function is defined as

$$
\phi(\tau)=\int_{-\infty}^{\infty} f(t) f(t+\tau) d t \quad .
$$

Figure 32 shows the autocorrelation function at $100 \mathrm{Mwt}$.

The square root of $\phi(0)$ gives the root-mean-square (rms) flux noise. Table $\mathrm{V}$ lists the rms noise under various conditions of power level, water level, pressure, boric acid concentration, control rod position, and whether the upper or lower feedwater ring was used.

c. Noise Frequency Spectrum. The Fourier transform of the autocorrelation function gives the energy density or power spectrum:

$$
\Phi(\omega)=\frac{1}{2 \pi} \int_{-\infty}^{\infty} \phi(\tau) \exp (-j \omega \tau) d \tau
$$

Figure 33 shows the 100-Mwt power spectrum. The 100-Mwt autocorrelation and power spectrum were computed with the IBM-704 digital computer, a total of 2000 samples being taken at $0.096-\mathrm{sec}$ intervals. The maximum shift $\tau$ used in computing the autocorrelation function was 200 samples. 


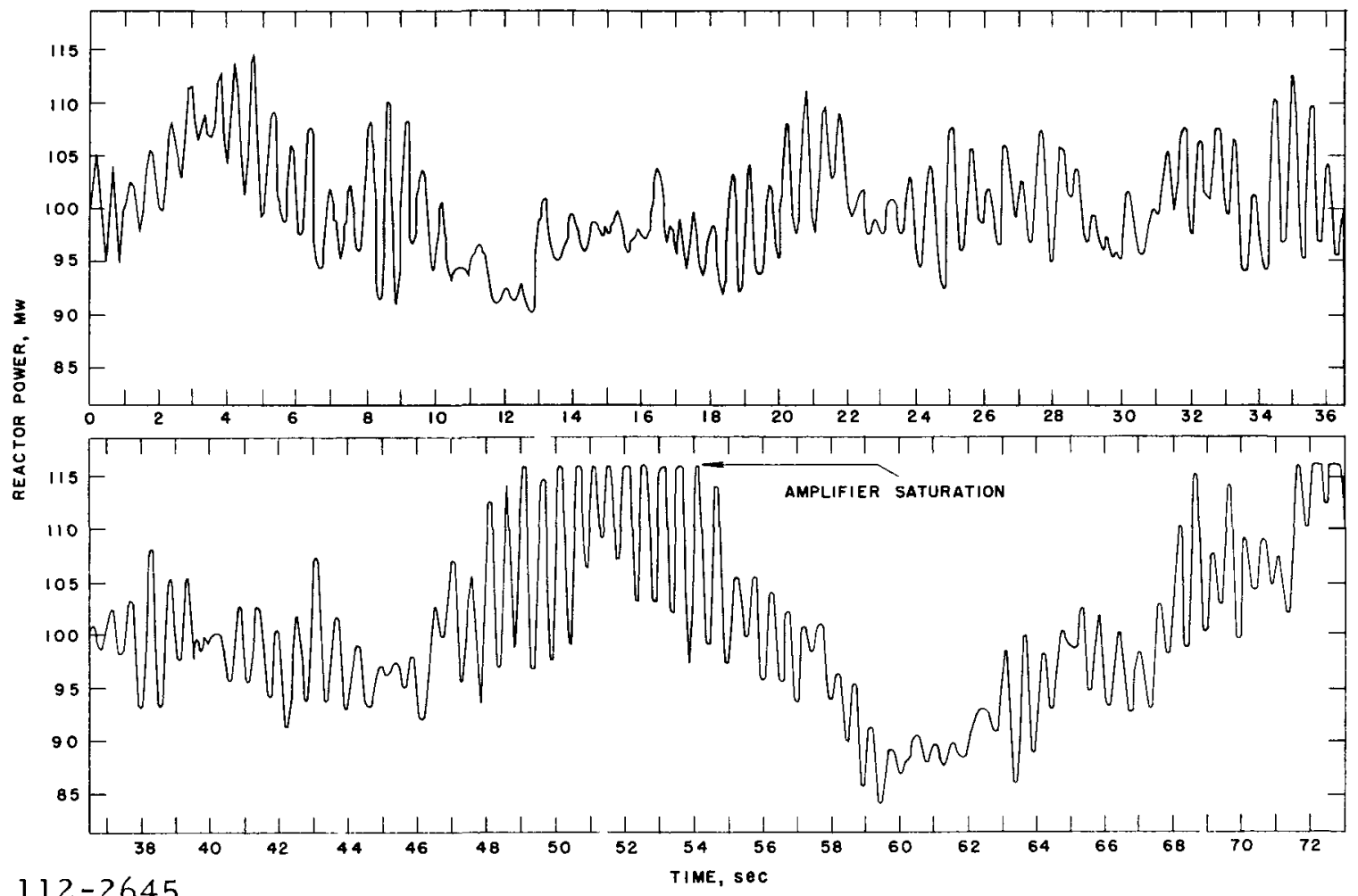

$112-2645$

Fig. 31. Reactor Power vs. Time as Recorded Directly from Ionization Chamber Output

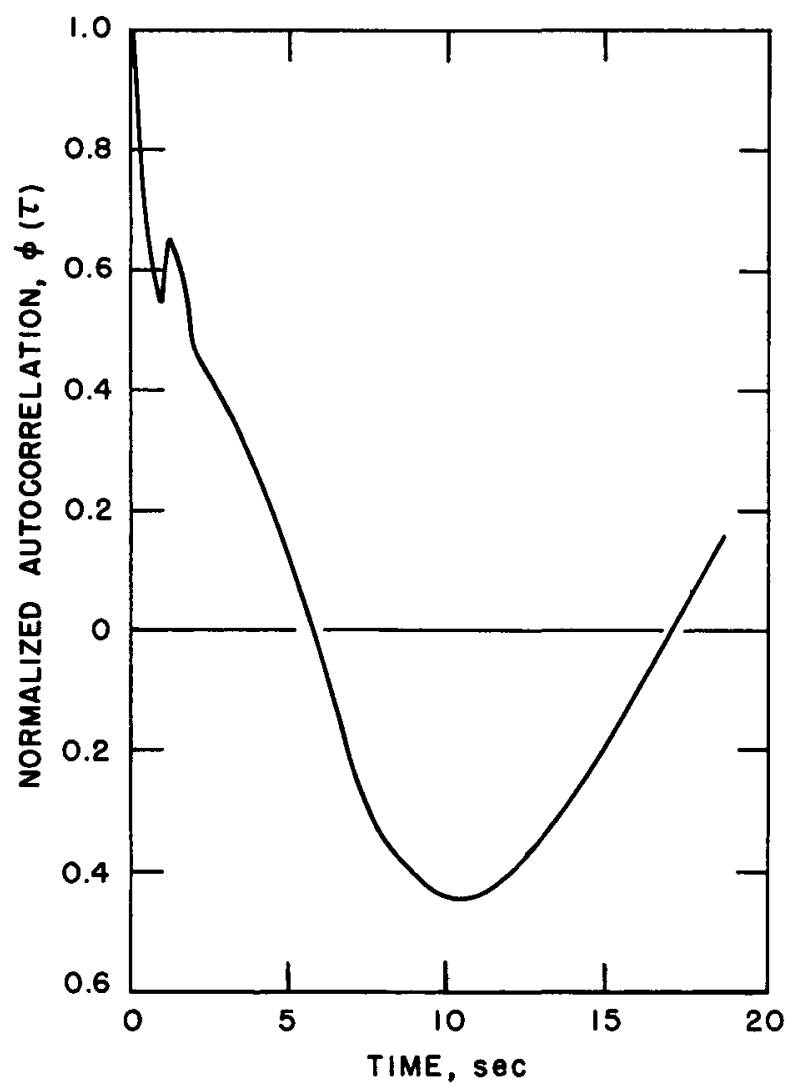

Fig. 32

Autocorrelation Function at $100 \mathrm{Mwt}$ 
Table V

ROOT-MEAN-SQUARE NOISE UNDER VARIOUS REACTOR OPERATING CONDITIONS

\begin{tabular}{|c|c|c|c|c|c|c|c|c|}
\hline \multirow[b]{2}{*}{$\begin{array}{l}\text { Pressure, } \\
\text { psig }\end{array}$} & \multirow[b]{2}{*}{$\begin{array}{c}\text { Power, } \\
\text { Mw }\end{array}$} & \multirow{2}{*}{$\begin{array}{l}\text { Water } \\
\text { Level, } \\
\text { ft-in. }\end{array}$} & \multirow{2}{*}{$\begin{array}{c}\text { Boric Acid } \\
\text { Concentration, } \\
\text { gm/gal }\end{array}$} & \multirow[b]{2}{*}{$\begin{array}{c}\text { Feedwater } \\
\text { Ring }\end{array}$} & \multirow[b]{2}{*}{$\begin{array}{c}\text { Rods } \\
1-8\end{array}$} & \multirow[b]{2}{*}{$\begin{array}{c}\text { Rod } \\
9\end{array}$} & \multicolumn{2}{|c|}{ rms Noise, $\%$} \\
\hline & & & & & & & Analog & Digital \\
\hline 300 & 10.0 & $16-0$ & 4.0 & Lowe $\mathrm{r}$ & 27.3 & 23.0 & 0.97 & 0.91 \\
\hline 300 & 10.0 & $16-0$ & 0.1 & Upper & 17.8 & 14.5 & 1.06 & 1.01 \\
\hline 300 & 20.0 & $16-0$ & 4.0 & Lower & 32.2 & 23.0 & 1.72 & 1.89 \\
\hline 300 & 20.0 & $16-0$ & 0.2 & Upper & 22.7 & 14.5 & 3.20 & 3.18 \\
\hline 600 & 11.5 & $16-0$ & 5.0 & Lower & 29.1 & 23.0 & 0.81 & 0.80 \\
\hline \multirow[t]{2}{*}{600} & 10.1 & $16-0$ & 0.2 & Upper & 18.7 & 14.5 & 0.90 & 1.23 \\
\hline & 10.0 & $16-0$ & 0.2 & Lowe $\mathbf{r}$ & 18.4 & 14.5 & 0.77 & 0.78 \\
\hline 600 & 13.4 & $16-0$ & 0.2 & Upper & & 14.5 & 1.31 & 1.38 \\
\hline 600 & 20.1 & $16-0$ & 3.9 & Lower & 30.0 & 23.0 & 0.97 & 1.01 \\
\hline 600 & 20.0 & $16-0$ & 0.1 & Upper & 22.4 & 14.5 & 1.88 & 1.96 \\
\hline 600 & 40.0 & $16-0$ & 0.2 & Upper & 29.2 & 21.5 & 3.27 & 3.20 \\
\hline 600 & 40.0 & $16-0$ & 2.7 & Upper & 48.0 & 30.0 & 4.28 & 4.01 \\
\hline 600 & 60.0 & $16-0$ & 0.5 & Upper & 48.0 & 30.0 & 5.64 & 4.96 \\
\hline 600 & 70.7 & $16-0$ & 1.1 & Upper & 40.6 & 30.0 & 6.26 & 7.43 \\
\hline 600 & 71.0 & $16-0$ & 1.0 & Upper & 34.7 & 39.8 & 4.72 & 4.55 \\
\hline 600 & 79.3 & $16-0$ & 1.1 & Upper & 35.2 & 39.8 & 5.20 & 5.15 \\
\hline $600^{*}$ & 74.8 & $16-0$ & 1.7 & Upper & 37.0 & 30.0 & 4.86 & 4.93 \\
\hline $600 *$ & 75.8 & $16-0$ & 1.7 & Upper & 34.6 & 34.6 & 4.11 & 4.04 \\
\hline $600 *$ & 76.8 & $16-0$ & 1.2 & Upper & 35.0 & 35.0 & 4.19 & - \\
\hline $600 *$ & 72.0 & $16-0$ & 1.2 & Upper & 34.0 & 40.0 & 3.66 & 3.45 \\
\hline $600 *$ & 82.0 & $16-0$ & 1.2 & Upper & 36.7 & 36.7 & 6.88 & 5.78 \\
\hline $600 *$ & 90.7 & $16-0$ & 1.2 & Uppex & 37.7 & 37.7 & 8.47 & 6.57 \\
\hline $600 *$ & 100.0 & $15-9$ & 0.1 & Upper & 48.0 & 48.0 & 6.01 & 6.77 \\
\hline $600 *$ & 60.0 & $16-0$ & 0 & Upper & 30.0 & 40.0 & 2.94 & 2.65 \\
\hline $600 *$ & 56.0 & $15-3$ & 0 & Upper & 32.0 & 40.0 & 1.38 & 1.35 \\
\hline $600 *$ & 60.7 & $15-3$ & 0 & Upper & 34.0 & 40.0 & 1.56 & 1.47 \\
\hline $600 *$ & 78.1 & $15-3$ & 0 & Upper & 48.0 & 48.0 & 2.65 & 2.59 \\
\hline $600 *$ & 74.7 & $16-0$ & 0 & Upper & 34.0 & 40.0 & 3.51 & 3.50 \\
\hline $600 *$ & 82.0 & $14-3$ & $?$ & Upper & 48.0 & 48.0 & - & 2.21 \\
\hline $600 *$ & 84.6 & $15-3$ & $?$ & Upper & 48.0 & 48.0 & - & 3.35 \\
\hline
\end{tabular}

*Automatic

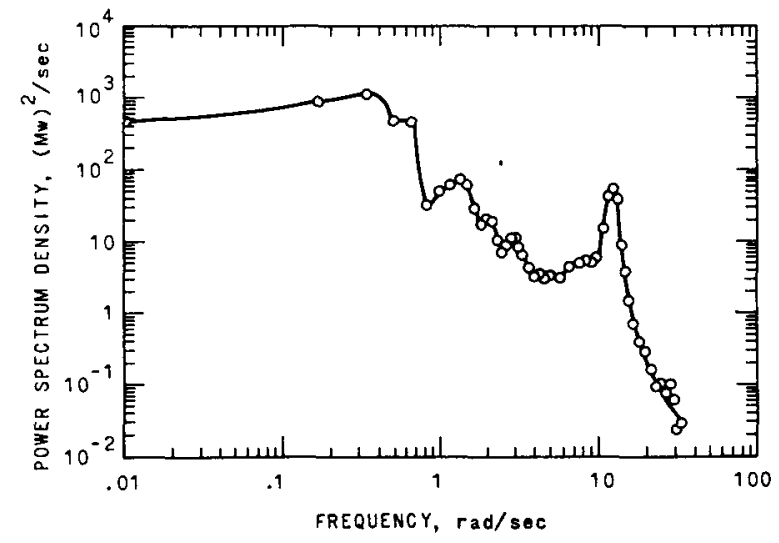

Fig. 33

Noise Frequency Spectrum at $100 \mathrm{Mwt}$ 
d. Random Reactivity Input. To utilize the digital techniques available more fully, the reactor was excited with a random reactivity. The randomness was of a particular nature referred to as fixed-interval binary noise; Fig. 34 shows a signal of this type. The control rod position is varied about a mean position in a random manner, but the change in position is allowed to take place only at fixed time intervals. The control rod mechanism on EBWR was velocity limited; consequently, the actual input waveform appeared as in Fig. 35.

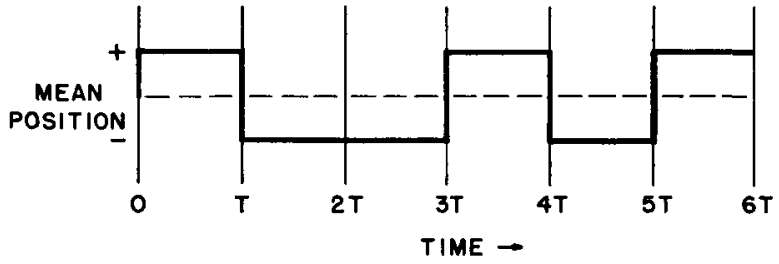

$112-2634$

Fig. 34. Discrete-interval, Binary Noise

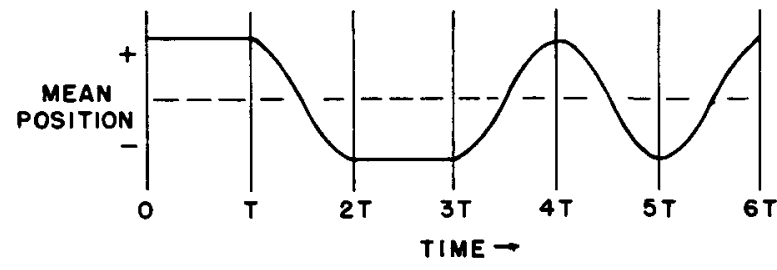

$112-2644$

Fig. 35. Velocity-limited, Discreteinterval, Binary Noise

The frequency spectrum for the EBWR velocity-limited, discrete-interval, binary noise signal is shown in Fig. 36. The frequency response of the reactor is obtained from the cross-correlation function and power-spectrum calculations. Figure 37 shows the frequency response of the reactor obtained by use of a binary noise input. The high-frequency portion of the figure was obtained with a binary time interval of 0.25 sec, and 9000 digital samples taken at 0.096 sec per sample. The low-frequency portion of the record was obtained with a binary time interval of $2.0 \mathrm{sec}$, and 9000 digital samples taken at 0.768 sec per sample.

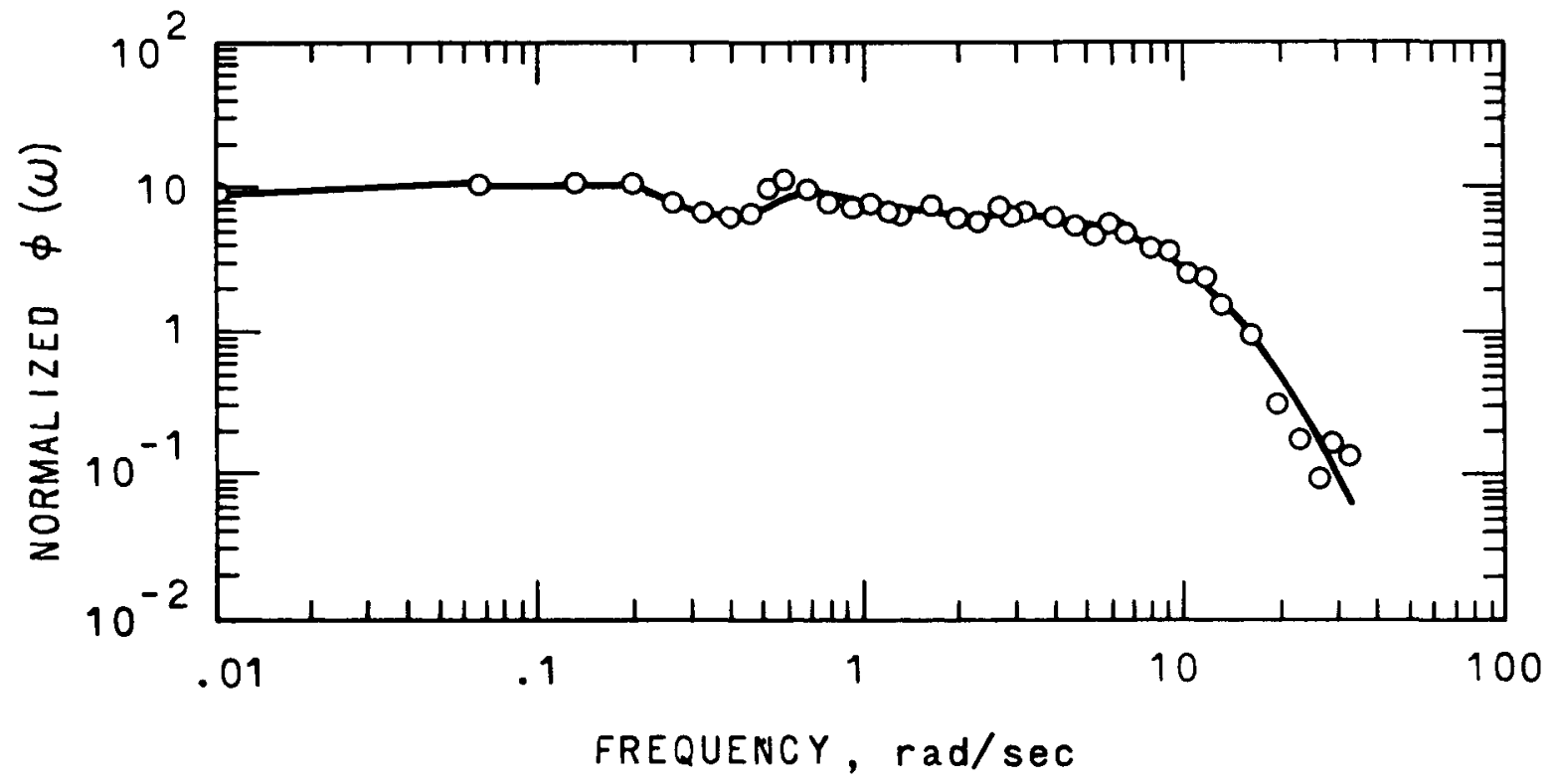

$112-2635$

Fig. 36. Velocity-limited, Discrete-interval, Binary Noise Frequency Spectrum 


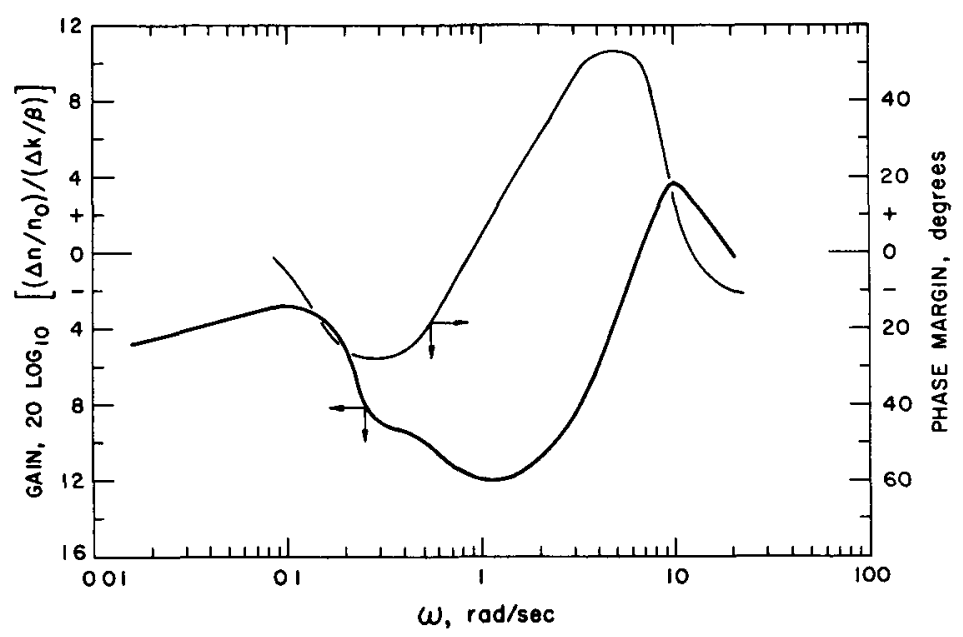

$112-2636$ Rev.

Fig. 37. Transfer Function at $40 \mathrm{Mwt}$ Obtained by Cross-correlation of Neutron Flux Output with Binary Noise

The amplitude and phase shift of Fig. 37 are in close agreement with the 40-Mwt measurement shown in Fig. 28, except for frequencies above 20 radians/sec. The velocity limitation imposed by the control rod mechanism resulted in the upper usable frequency limit of 20 radians/sec. This frequency limit does not allow the data of Fig. 37 to be normalized to the zero-power transfer function; consequently, the binary noise technique was not used at higher powers. It should be noted that the high-frequency response portion of Fig. 37 was obtained in 15 min of reactor experimentation time, as compared with 15 min for a single frequency point when using a sinusoidal excitation.

\section{Summary}

Reactor transfer functions are useful tools in studying reactor performance. Predictions of stability at higher powers can be obtained by extrapolation so that increases in power can be made with confidence. The powe $r$ at which instability will develop also can be predicted.

These data can be used to develop a dynamic model which combines all the design parameters - reactor physics, heat transfer, and hydraulics - for the specific reactor type under investigation. The dynamic model is more descriptive of reactor performance than are static measurements, e.g., reactivity per unit power or unit void per unit power. The development of a correct model then assures success in optimizing the performance on the next generation of similar reactors. 


\section{ACKNOW LEDGMENT}

The authors gratefully acknowledge the assistance, during the program, by the following staff members, Reactor Engineering Division, Argonne National Laboratory:
A. Hirsch
W. Knapp
E. Martinec
J . Matousek
G. Popper
E. Spleha
H. Till*

Control and Instrumentation Flux Measurements and Water Control

Design and Operation

Design and Operation

Transfer Function Instrumentation

Experimental Hydraulic Instrumentation

Radiation Survey Data

*Industrial Hygiene and Safety Division. 
1. J. M. Harrer et al., Performance Evaluation of Direct-cycle Boiling Water Nuclear Powe r Plants Based on Recent EBWR-Borax Data, Proc. Second UN Intn'l Conf. on Peaceful Uses of Atomic Energy, Geneva, Switzerland, 9, 264 (1958).

2. J. F. Matousek, Modification of the Experimental Boiling Water Reactor (EBWR) for Higher Power Operation, ANL-6552 (Supplement to ANL-5607) (April 1962).

3. R. F. S. Robertson, Tests of Defected Thoria-Urania Fuel Specimens in EBWR, ANL-6022 (June 1960).

4. M. Petrick and E. A. Spleha, Thermal Hydraulic Performance Characteristics of EBWR, 0-100 Mwt, ANL-6693 (May 1963).

5. EBWR Test Reports Associated with the 100-Mw Facility, ANL-6703 (to be published).

6. M. Petrick, A Study of Vapor Carryunder and Associated Problems, ANL-6581 (July 1962).

7. H. P. Iskenderian, Physics of EBWR Core Loading IA, ANL-6776 (to be published).

8. W. G. Knapp, Neutron-flux Studies in the EBWR during Power Operation, ANL-675l (to be published).

9. W. C. Lipinski, et al., EBWR Dynamic Behavior up to $100 \mathrm{Mw}$, ANL-6777 (to be published).

10. R. Avery et al., EBWR Core IA Physics Analysis, ANL-6305 (Feb 1961). 
The EBWR (Experimental Boiling Water Reactor), ANL-5607 (May 1957).

J. A. Thie, EBWR Physics Experiments, ANL-5711 (July 1957).

J. A. DeShong, Jr. and E. S. Beckjord, Frequency Response Measurements of the EBWR Automatic Steam Bypass Valve Control System, ANL-5726 (June 1957).

J. M. West et al., Hazard Summary Report on the Experimental Boiling Water Reactor (EBWR), ANL-5781.

E. A. Wimunc and J. M. Harrer, Hazards Evaluation Report Associated with the Operation of EBWR at $100 \mathrm{Mw}$, ANL-5781 Addendum (Revision 1) (Oct 1960).

J. A. DeShong, Jr., Power Transfer Functions of the EBWR Obtained Using a Sinudoidal Reactivity Driving Function, ANL-5798 (Jan 1958).

E. S. Beckjord, Dynamic Analysis of Natural Circulation Boiling Water Power Reactors, ANL-5799 (March 1958).

J. A. Thie, Dynamic Behavior of Boiling Reactors, ANL-5849 (May 1959).

J. A. DeShong, Jr. and W. C. Lipinski, Analyses of Experimental Powerreactivity Feedback Transfer Functions for a Natural Circulation Boiling Water Reactor, ANL-5850 (July 1958).

Proceedings of the Conference on Transfer Function Measurement and Reactor Stability Analysis, Held at Argonne National Laboratory, Argonne, Illinois, May 2-3, 1960, ANL-6205 (May 2-3, 1960).

A. Z. Akcasu, Theoretical Feedback Analysis in Boiling Water Reactors, ANL-6221 (Oct 1960).

V. M. Kolba, EBWR Test Reports, ANL-6229 (Nov 1960).

H. Christensen, Power-to-Void Transfer Functions, ANL-6385 (July 1961).

N. Suda and F. Rehbach, Dynamic Analysis of the Operation of EBWR at $100 \mathrm{Mw}$, ANL-6478 (Dec 1961).

Papers Presented at the Technical Briefing Session Held at Argonne National Laboratory, May 27 and 28, 1957, TID-7535 (Oct 1957). 